\title{
Folic acid targeted Mn:ZnS quantum dots for theranostic applications of cancer cell imaging and therapy
}

\author{
Ibrahim Birma \\ Bwatanglang ${ }^{1,2}$ \\ Faruq Mohammad ${ }^{3}$ \\ Nor Azah Yusof ${ }^{1,3}$ \\ Jaafar Abdullah' \\ Mohd Zobir Hussein ${ }^{3}$ \\ Noorjahan Banu Alitheen ${ }^{4}$ \\ Nadiah $\mathrm{Abu}^{4}$ \\ 'Department of Chemistry, Faculty \\ of Science, Universiti Putra Malaysia, \\ Serdang, Selangor, Malaysia; \\ ${ }^{2}$ Department of Chemistry, Faculty \\ of Science, Adamawa State University, \\ Mubi, Nigeria; ${ }^{3}$ Institute of Advanced \\ Technology, ${ }^{4}$ Department of Cell \\ and Molecular Biology, Faculty of \\ Biotechnology and Biomolecular \\ Science, Universiti Putra Malaysia, \\ Serdang, Selangor, Malaysia
}

This article was published in the following Dove Press journal:

International Journal of Nanomedicine

22 January 2016

Number of times this article has been viewed

\begin{abstract}
In this study, we synthesized a multifunctional nanoparticulate system with specific targeting, imaging, and drug delivering functionalities by following a three-step protocol that operates at room temperature and solely in aqueous media. The synthesis involves the encapsulation of luminescent Mn:ZnS quantum dots (QDs) with chitosan not only as a stabilizer in biological environment, but also to further provide active binding sites for the conjugation of other biomolecules. Folic acid was incorporated as targeting agent for the specific targeting of the nanocarrier toward the cells overexpressing folate receptors. Thus, the formed composite emits orange-red fluorescence around $600 \mathrm{~nm}$ and investigated to the highest intensity at $\mathrm{Mn}^{2+}$ doping concentration of 15 at.\% and relatively more stable at low acidic and low alkaline $\mathrm{pH}$ levels. The structural characteristics and optical properties were thoroughly analyzed by using Fourier transform infrared, X-ray diffraction, dynamic light scattering, ultraviolet-visible, and fluorescence spectroscopy. Further characterization was conducted using thermogravimetric analysis, high-resolution transmission electron microscopy, field emission scanning electron microscopy, energy dispersive X-ray spectroscopy, X-ray fluorescence, and X-ray photoelectron spectroscopy. The cell viability and proliferation studies by means of MTT assay have demonstrated that the as-synthesized composites do not exhibit any toxicity toward the human breast cell line MCF-10 (noncancer) and the breast cancer cell lines (MCF-7 and MDA-MB-231) up to a $500 \mu \mathrm{g} / \mathrm{mL}$ concentration. The cellular uptake of the nanocomposites was assayed by confocal laser scanning microscope by taking advantage of the conjugated Mn:ZnS QDs as fluorescence makers. The result showed that the functionalization of the chitosan-encapsulated QDs with folic acid enhanced the internalization and binding affinity of the nanocarrier toward folate receptoroverexpressed cells. Therefore, we hypothesized that due to the nontoxic nature of the composite, the as-synthesized nanoparticulate system can be used as a promising candidate for theranostic applications, especially for a simultaneous targeted drug delivery and cellular imaging.
\end{abstract}

Keywords: $\mathrm{Mn}: \mathrm{ZnS}$, quantum dots, theranostics, folic acid, cancer diagnosis, fluorescence imaging

\section{Introduction}

In recent years, the development of an integrated nanotherapeutic system which can allow for an online imaging and deliver targeted therapy has been the subject of interest in clinical oncology. This emerging nanotechnology has allowed the manipulation of nanoparticles (NPs) to assume multiple functionalities. ${ }^{1-4}$ Interestingly in that view, the use of multifunctional quantum dots (QDs) as fluorescence imaging contrast agents as compared with the traditional organic fluorophores has significantly enhanced both in vitro and in vivo detection and online assessment of cancer tumors in animal models. ${ }^{4,5}$ The preference of QDs as optical imaging contrast agents as compared
Correspondence: Faruq Mohammad; Nor Azah Yusof

Institute of Advanced Technology, Universiti Putra Malaysia, 43400 Serdang, Selangor, Malaysia

Tel +60389467503

Email faruq_m@upm.edu.my; azahy@ upm.edu.my 
with the latter is largely due to its intrinsic ability to resist photobleaching. ${ }^{6,7}$ Fluorescence semiconductors offer advantages in that, as they have a broad and tunable absorption spectrum extending from the ultraviolet (UV) toward the visible (UV-Vis) region. ${ }^{8}$ Semiconductor nanocrystals such as bulk zinc sulfate $(\mathrm{ZnS})$ emits high fluorescence with a color that depends on the particle size but regrettably suffers from self-quenching effects. The doping of $\mathrm{ZnS}$ with other impurities such as $\mathrm{Mn}^{2+}$ and $\mathrm{Cd}^{2+}$ are reported to significantly reduce this intrinsic quenching behavior and at the same time enhances the fluorescence efficiency of the QDs toward the cut-off wavelength of the visible region. ${ }^{8}$ Interestingly, the similarity in the ionic radii and valence state of the $\mathrm{Mn}^{2+}$ and those of $\mathrm{Zn}^{2+}$ ions allowed for an easy substitution to take place in the host $\mathrm{ZnS}$ crystals. ${ }^{9}$ The $\mathrm{Mn}^{2+}$ ion in this regard serves as the luminescence center by providing recombination sites for the electrons and holes as charge carriers. The resultant transfer of electrons and hole charges into the electronic level of $\mathrm{Mn}^{2+}$ ions allow for the emission of a characteristic orange-red fluorescence following ${ }^{4} \mathrm{~T}_{1}-{ }^{6} \mathrm{~A}_{1}$ transition of the $\mathrm{Mn}^{2+}$ ion. ${ }^{10-12}$ By the application of appropriate bioconjugation, the orange-red fluorescence emission from the doped $\mathrm{Mn}^{2+}$ in the $\mathrm{ZnS}$ nanocrystals can conveniently replace the conventional organic fluorophore in molecular imaging and quantitative cellular studies. , $7,9^{-1}$

Several researchers have explored novel approaches for the synthesis of water-soluble QDs through the selection of appropriate stabilizers such as 3-mercaptopropionic acid (MPA), mercaptoacetic acid, thioglycolic acid (TGA), polysaccharide copolymers, etc. ${ }^{4,13}$ However, some researchers observed that the quantum yield obtained from QDs stabilized by thiol-groups is usually low. ${ }^{14-16}$ Furthermore, the thiol-QD bond is also reported not to be very stable and precipitates readily on being dialyzed against buffer solution and water with time. ${ }^{17,18}$ In addition to this finding, MPA, one of the common stabilizers used for the synthesis of water-soluble QDs, is a volatile liquid with strong odor and is reported to be carcinogenic in nature and environmentally unfriendly. Thus, the use and application of MPA as water-soluble stabilizer is not entirely green chemistry approach. ${ }^{19}$ In this regard, chitosan (CS), a natural copolymer of $N$-acetylglucosamine and D-glucosamine has drawn greater attention as stabilizer of choice for the encapsulation of QDs. CS is highly biocompatible, nontoxic and environmentally friendly and helps to render QDs as water soluble. ${ }^{4,17}$ In addition to these qualities, the large functional backbone of CS can equally serves as a viable platform for the encapsulation of drugs and other suitable ligands. ${ }^{9,20}$ This unique signature of CS in addition to being a stabilizer and drug delivery vehicle, also protects the conjugated QDs and reduces the possibility of nonspecific protein opsonization. ${ }^{17,21}$

From a biomedical point of view, the $\mathrm{Mn}^{2+}$-doped $\mathrm{ZnS}$ (Mn:ZnS) conjugated CS nanocarrier can be made to achieve active or selective targeting and imaging of diseases by attaching suitable ligands with strong binding affinity toward the largely expressed receptors such as proteins, vitamins, monoclonal antibodies, aptamers, and peptides. ${ }^{22,23}$ These among many have been reported in the development of a number of theranostic applications that included targeted drug delivery using receptor-mediated pathways for the detection of cancerous tumors or following protein-protein interactions toward the detection of proteins in blood assays. ${ }^{24-26}$ The active targeting has attracted considerable interest due to its target specificity unlike the passive targeting, which takes advantage of leaky vasculature found in cancerous cells through enhanced permeability and retention effects to transport the drug. ${ }^{27}$ Under these processes, there exists the possibility of the required dosage being lost on transit before reaching the diseased site. ${ }^{28}$ In that view, folic acid (FA), a nontoxic low-weight vitamin is found to have strong binding affinity toward folate receptors (FRs) largely secreted by cancerous cells as compared with the normal cells. ${ }^{21}$ Though FA was successfully conjugated directly to the surface of metallic nanoparticles (MNPs) such as QDs, ${ }^{29}$ some researchers observed that this often resulted in the oxidation of the surface and possible changes in the optical chemistry of the MNPs and the unprotected or naked MNPs were exposed to the scavenging effects of blood matrix species. ${ }^{21}$ Thus, in our work the FA was first conjugated to CS and following this conjugation, the QDs were then encapsulated. It is therefore hypothesized that the functionalization of $\mathrm{Mn}: \mathrm{ZnS}$ conjugated CS with FA and encapsulation with an anticancer drug helps to achieve triple purpose: 1) enabling specific targeting of folate-expressed cancer cells; 2) as a vehicle for stabilizing and transporting drugs to the tumor-targeted sites; and 3) the highly intense fluorescent emission from $\mathrm{Mn}^{2+}$ can be used for noninvasive imaging of the cancer cells.

Here, we present an aqueous, room temperature synthesis of fluorescence Mn:ZnS QDs loaded onto CS biopolymer and conjugated to FA for specific targeting of FR-overexpressed cancer cells following modified protocols reported elsewhere. ${ }^{4}$ In this study, we intentionally avoided the use of lengthy spacer groups so as to retain the structural integrity of our materials as much as possible, and also avoided the rigor of chemical modification that may introduce possible structural defects and/or alteration of the electronic states 
of the core material. ${ }^{28-31}$ It has been demonstrated that the FA conveniently binds to the surface of metals via noncovalent interactions ${ }^{31,32}$ and similar method of interaction with CS were also reported. ${ }^{33}$ In this particular instance, the conjugation of the FA and CS is initiated due to the strong electrostatic interaction of the cationic amino groups of CS with the anionic carboxylate group of FA; the result shows a loading efficiency of approximately $30.5 \pm 1.2 \mathrm{wt} . \%{ }^{33}$ Despite the successes recorded following noncovalent method of conjugation of FA to other biomolecules or MNPs, ${ }^{29-34}$ several work reported a superior performance following covalent methods of interactions. ${ }^{4,35,36}$ However, the greatest challenge is meeting the requirements of specific conjugation chemistry that retains QDs biochemical activity as much as possible. Despite the superiority of covalent coupling of FA to QDs by means of 1-ethyl-3-(3-dimethylaminopropyl) carbodiimide-based chemistry, some researchers reported that 1-ethyl-3-(3-dimethylaminopropyl)carbodiimide has short half-life in water and results in poor coupling efficiency. Although the addition of $N$-hydroxysuccinimide may have improved the efficiency, ${ }^{36}$ it is considered to follow lengthy pathways that may probably modify the biochemical integrity of the QDs/NPs. In the same vein, other researchers reported that the proteins readily lost their structural integrity upon adsorption onto monolayer-protected metal NPs (or QDs) following covalent interactions, leading to instability and subsequent denaturation. ${ }^{37}$ It is also investigated that the drug whose active site is covalently bound to the surface of NPs are observed not to undergo controlled drug release readily as compared with drugs encapsulated by following noncovalent interactions. ${ }^{38}$ Therefore for controlled and targeted delivery, formulation of nanocarriers with noncovalent interactions may be the probable method of preserving the active ingredients and structural integrity of the materials as much as possible. Hence, the nonchemical methods adopted in this work follows simple ultrasonication, centrifugation, and controlled $\mathrm{pH} \cdot{ }^{29-33}$

\section{Materials and methods Chemicals}

Low-molecular-weight CS (75\%-85\% degree of deacetylation) was purchased from Sigma-Aldrich (St Louis, MO, USA), while the other chemicals such as ethanol (99.5\%) was purchased from Fisher Scientific (Selangor, Malaysia) and acetic acid (99.85\%) from Benson Lab Chemicals (Selangor, Malaysia). Zinc acetate dehydrate $\left(\mathrm{Zn}(\mathrm{OAc})_{2} \cdot 2 \mathrm{H}_{2} \mathrm{O}\right) 99.5 \%$, FA $\left(\mathrm{C}_{19} \mathrm{H}_{9} \mathrm{~N}_{7} \mathrm{O}_{6}, 98 \%\right)$, sodium sulfide $\left(\mathrm{Na}_{2} \mathrm{~S} \cdot \mathrm{XH}_{2} \mathrm{O}\right)$, manganese sulfate $\left(\mathrm{MnSO}_{4} \cdot \mathrm{H}_{2} \mathrm{O}, 99 \%\right)$, and sodium tripolyphosphate
$\left(\mathrm{Na}_{5} \mathrm{O}_{10} \mathrm{P}_{3}, 59 \%\right)$ were purchased from R\&M Marketing (Essex, UK). Deionized water was used across all treatments.

\section{Synthesis of folic acid-chitosan stabilized $\mathrm{Mn}^{2+}$-doped ZnS QDs}

For the preparation of folic acid-chitosan stabilized $\mathrm{Mn}^{2+}$ doped ZnS (FACS-Mn:ZnS) QDs, the three sequential steps involved are demonstrated schematically in Figure 1.

The first step involves the formation of stable FA and CS suspension and for that, we prepared $5 \mathrm{~mL}$ (at $4 \mathrm{mg} / \mathrm{mL}$ concentration) of water-soluble CS by protonating the $-\mathrm{NH}_{2}$ group with $1 \%$ acetic acid ${ }^{39}$ under stirring while adjusting the $\mathrm{pH}$ to 5.4 using $0.1 \mathrm{M} \mathrm{NaOH}$. Further, $2 \mathrm{~mL}$ of $1 \mathrm{mg} / \mathrm{mL}$ FA in distilled water was prepared separately and stirred for 1 hour to form FA solution and the resulting solution was then added to the $\mathrm{CS}$ solution dropwise under constant stirring for 2 hours. Now $2 \mathrm{~mL}$ of $1 \mathrm{mg} / \mathrm{mL}$ tripolyphosphate was added as a cross-linker drop by drop to the mixture and stirred for 8 hours to form the stable suspension of FACS. The second step involves the synthesis of highly luminescent $\mathrm{Mn}: \mathrm{ZnS}$ QDs following simple modified wet method as described by Mathew et al. ${ }^{4}$ Briefly, $1.5 \mathrm{~mL}$ of $\mathrm{MnSO}_{4}$ (varying at. \%) was prepared and added dropwise to $10 \mathrm{~mL} \mathrm{Zn(OAc)})_{2}(0.1 \mathrm{M})$ under ultrasonication and stirred well by bubbling with $\mathrm{N}_{2}$ gas for 15 minutes. To the resulting mixture, $10 \mathrm{~mL}$ of $\mathrm{Na}_{2} \mathrm{~S}$ $(0.1 \mathrm{M})$ was added drop by drop under constant stirring to form a white precipitate in the process while maintaining the $\mathrm{pH}$ to 5.4. The doping processes were observed for the emission of orange fluorescence under handheld UV lamp. In order to suppress unwanted relaxation phenomenon from dominating the energy pathways, the obtained precursor was immediately exposed to microwave irradiation for 1 minute and further stirred for 1 hour. ${ }^{4,10}$ The conjugation of FACS to the Mn:ZnS QDs was carried in the third step and for that, the Mn:ZnS QDs as prepared above was added dropwise to the $10 \mathrm{~mL}$ FACS solution under ultrasonication, allowed to sonicate for 10 minutes and stirred for another 1 hour. Following the stirring, the resulting precursor was centrifuged at 4,000 rpm for 10 minutes. The supernatant was separated and the precipitate was washed with $98 \%$ ethanol. The centrifugation and washing procedure was repeated thrice and finally, the wet pellet was collected and air dried for 2 days to obtain the powder of FACS-Mn:ZnS nanocomposite.

\section{Instrumental analysis}

For the characterization of FACS-Mn:ZnS composite, different instruments were applied at various stages of the analysis; for example, the particle size and surface morphology was 

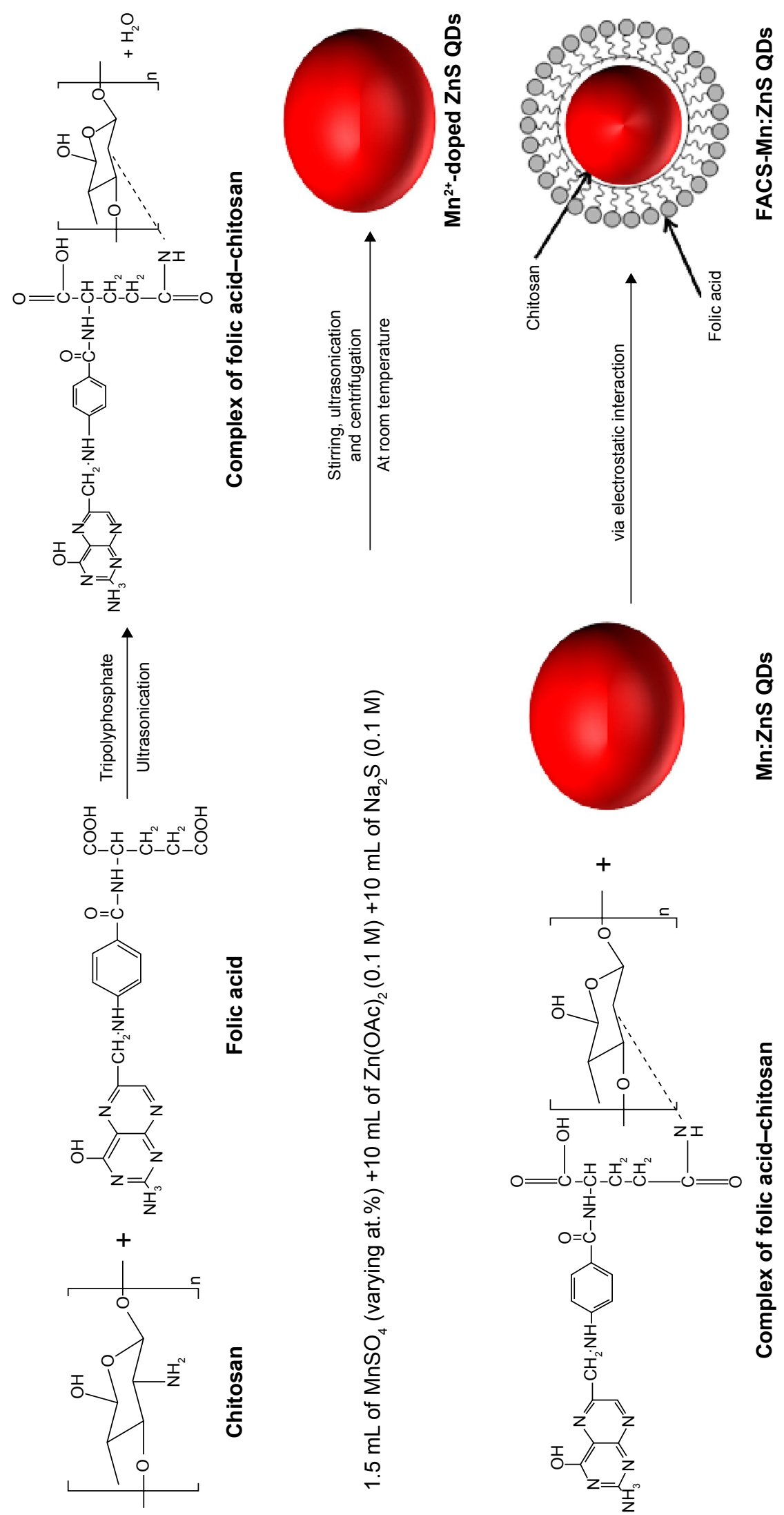

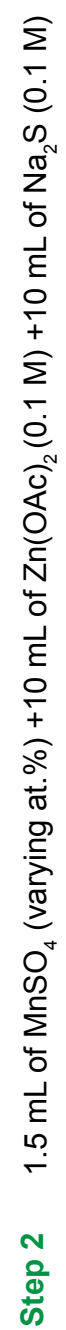

응
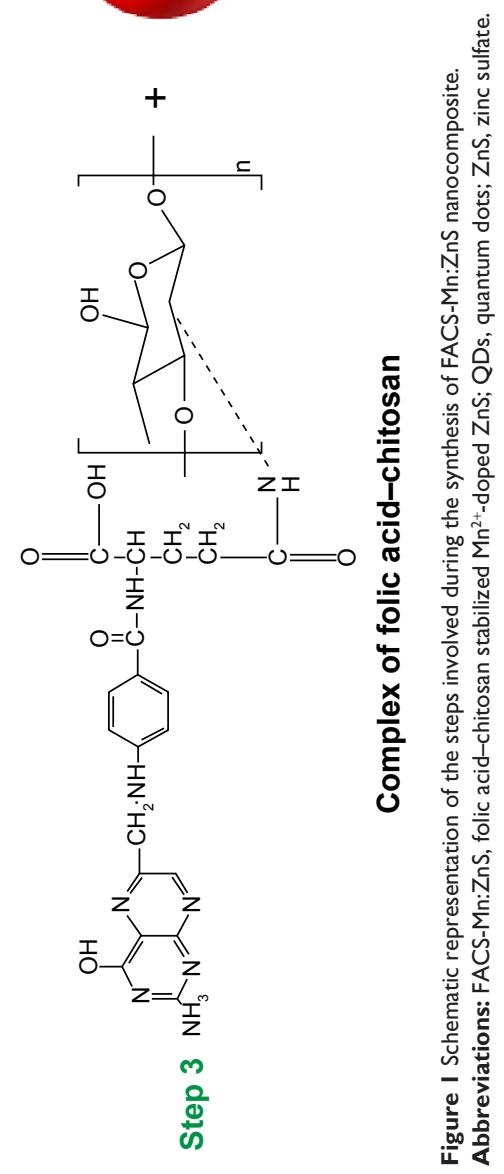
determined using high-resolution transmission electron microscopy (HRTEM) collected on Tecnai G2 F20 (FEI company, Hillsboro, OR, USA) and the samples were prepared by dispersing the particles in distilled water and drop casted onto a carbon-coated copper grid. Similarly, gold sputtered samples were prepared and collected on a sample holder attached to a constructive aluminum foil using carbon adhesive for further morphology studies using field emission scanning electron microscopy (FESEM) on JEOL JSM-7600F (JEOL, Tokyo, Japan). Elemental analysis of the samples were simultaneously recorded using the same instrument attached to energy dispersive analysis X-ray (EDAX) analyzer by focusing the electron beam onto the particles and the spectrums were obtained through the random capturing of micrographs. X-ray photoelectron spectroscopy (XPS) measurements were carried out at a pressure of $10^{-9}$ mbar, using PHI Quantera II (ULVACPHI, Inc, Chigasaki, Japan) instrument operating with an AlKo monochromatic source. Fourier transform infrared (FTIR) analysis was conducted on the samples over 4,500-500 $\mathrm{cm}^{-1}$ wavenumber region at a resolution of $8 \mathrm{~cm}^{-1}$ with 1,024 scan using Spectrum 100 (PerkinElmer, Waltham, MA, USA). For that, the transparent pellets of the samples were prepared by grinding the material with dry powder of potassium bromide.

For the X-ray fluorescence (XRF) analysis, approximately $1 \mathrm{~g}$ of the sample was mixed with $6 \mathrm{~g} \mathrm{H}_{3} \mathrm{BO}_{3}$ and pressed under 10 tons of pressure and was used to further determine the elemental composition using XRF-energy dispersive X-ray spectroscopy (EDX) 720, wavelength-dispersive spectrometer (Shimadzu, Kyoto, Japan) equipped with an array of five analyzing crystals fitted with $\mathrm{Rh}$ X-ray tube target. The dynamic light scattering (DLS) analyses were conducted to measure the average particle size and distribution of the particles in solution phase with the help of Malvern Nano series, Zetasizer instrument (Malvern Instruments, Malvern, UK). The dispersed sample in deionized water was collected in a cuvette and triplicate measurement was taken as mean \pm standard deviation (SD). The crystallinity of the sample was determined using powder X-ray diffraction (XRD) instrument XRD 6000 (Shimadzu) and the crystal structure was analyzed using nickel-filtered $\mathrm{CuK} \alpha$ radiation. The thermographic analysis (TGA) was conducted on a TG 7 PerkinElmer instrument at a heating rate of $10^{\circ} \mathrm{C} \mathrm{min}{ }^{-1}$ in nitrogen atmosphere and the weight losses up to $600^{\circ} \mathrm{C}$ was recorded. The UV-Vis spectroscopic analyses were carried out on PerkinElmer Lambda 35 spectrometer by dispersing the samples in deionized water in a wavelength range of 200-500 nm. For the fluorescence measurements, Shimadzu spectrofluorimeter, RF-5301PC was used and the samples were prepared by dispersing in deionized water and the measurements were conducted at slit width kept at $5 \mathrm{~nm}$ on both $328 \mathrm{~nm}$ excitation wavelength. The microscopic fluorescence imaging was conducted using confocal microscopy, Olympus FV1000 (Singapore), with silicone immersion and oil- and water-immersion objectives equipped with gallium phosphine detector (Olympus).

\section{In vitro cell viability and fluorescent imaging study}

The cell viability was assessed based on the metabolic activity of the cells to reduce a soluble yellow tetrazolium salt (MTT dye, 3-(4,5-dimethylthiazol-2-yl)-2,5-diphenyltetrazolium bromide) to blue-violet formazan crystals. ${ }^{40}$ Briefly, two different human breast cancer cell lines, MCF-7 and MDAMB-231 and one healthy normal breast cell line, MCF-10 were maintained separately in Dulbecco's Modified Eagle's Medium (DMEM) supplemented with 10\% (v/v) fetal bovine serum (FBS) and 1\% antibiotics (penicillin, 100 units $/ \mathrm{mL}$; streptomycin, $100 \mu \mathrm{g} / \mathrm{mL}$ ) in an incubator at $37^{\circ} \mathrm{C}, 5 \%$ $\mathrm{CO}_{2}$, and in $95 \%$ humidity. Approximately $10^{4}$ cells/well were seeded onto 96-well plates and allowed to grow for 24 hours. At approximately $80 \%$ cell confluence level, the medium was replaced with fresh DMEM containing $2 \%(\mathrm{v} / \mathrm{v})$ FBS and varying concentrations $(7-500 \mu \mathrm{g} / \mathrm{mL})$ of FACS$\mathrm{Mn}: \mathrm{ZnS}$ with phosphate-buffered saline (PBS) (pH 7.4) and incubated for another 24 hours. Following the incubation period, $20 \mu \mathrm{L}$ of MTT $(5 \mathrm{mg} / \mathrm{mL})$ was added and incubated for another 3-4 hours. After the incubation, the solution was removed and $100 \mu \mathrm{L}$ dimethyl sulfoxide (DMSO) was added; the solubilized crystals were measured at $570 \mathrm{~nm}$ using the $\mu$ Quant $^{\mathrm{TM}}$ enzyme-linked immunosorbent assay plate reader (BioTek Instruments, Winooski, VT, USA). The percentage cell viability was then calculated with respect to the untreated control (set at $100 \%$ ) and the values were taken as mean \pm SD of three replicate experiments.

For the cell imaging study, the respective cells were separately maintained in DMEM supplemented with $10 \%$ (v/v) FBS and 1\% antibiotics (penicillin, 100 units $/ \mathrm{mL}$; streptomycin, $100 \mu \mathrm{g} / \mathrm{mL}$ ) in an incubator at $37^{\circ} \mathrm{C}, 5 \%$ $\mathrm{CO}_{2}$, and in $95 \%$ humidity. The cells were washed with PBS ( $\mathrm{pH} 7.4$ ) and seeded at two different densities $2 \times 10^{4}$ and $3 \times 10^{3}$ per well onto a cover glass inside of 24 -well plate. Further washing of cells were conducted using PBS and replaced with a fresh media containing the FACS-Mn:ZnS composite $(100 \mu \mathrm{g} / \mathrm{mL})$ and incubated for 4 hours at $37^{\circ} \mathrm{C}$. The cells were finally washed with PBS and fixed with $2 \%$ formaldehyde and mounted with 
mounting medium and imaged. The microscopic fluorescence imaging was conducted using confocal microscopy, Olympus (FluoView F1200) with silicone immersion and oil- and water-immersion objectives equipped with gallium phosphine detector. The fluorescence generated by the QDs was captured using effective excitation $360 \mathrm{~nm}$ and 550-640 $\mathrm{nm}$ emission filters.

\section{Results and discussion}

In the present study, FACS-Mn:ZnS QDs were prepared specifically for theranostic applications by combining the targeted drug delivery and imaging capabilities of FA and QDs, respectively. The formed composite particles were thoroughly characterized for their size, morphology, crystalline behavior, thermal stability, etc, and also tested for cytobiocompatibility studies to suite as safe drug delivery vehicles. Further, the in vitro fluorescence imaging studies on cancer and noncancer cells were conducted in order to establish the luminescent efficiency of the conjugated contrast agents for live cell imaging of cancerous tumors.

The FESEM and EDAX analysis of FACS-Mn:ZnS QDs are shown in Figure 2A and B and from the microscopic image, the particles seem to be agglomerated due to the over conjugation of QDs with that of CS biopolymer (Figure 2A). Also, from the EDAX spectrum shown in Figure 2B, one can clearly see the presence of corresponding peaks related to specific elements of interest in the composite. The major peaks corresponding to $\mathrm{Zn}$ and $\mathrm{S}$ are the indications for the presence of $\mathrm{Zn}-\mathrm{S}$ matrix in the composite..$^{41}$ Interestingly, despite the small amount of $\mathrm{Mn}^{2+}$ impurities doped into the $\mathrm{ZnS}$ matrix, we were able to see a minor peak corresponding to $\mathrm{Mn}^{2+}$ in the final composite. As seen from the spectrum, the presence of $\mathrm{Au}$ is from the Au sputtered sample grid used in the FESEM analysis. ${ }^{42}$ The HRTEM image, particle size distribution from TEM (in powder phase), and DLS analysis (in solution phase) are shown in Figure 2C-E, respectively. From the Figure $2 \mathrm{C}$, the particles are seem to be spherical and uniform but are fully agglomerated as similar to the result of FESEM (Figure 2A). For the FACS-Mn:ZnS particles, an average particle size of $5.3 \pm 1.0 \mathrm{~nm}$ is observed from the TEM analysis (Figure 2D), while $\sim 200 \mathrm{~nm}$ hydrodynamic size is observed from the DLS analysis (Figure 2E). The differences in particle sizes between the TEM (recorded in powder form) and DLS analysis (recorded in solution form) can be attributed to the swelling behavior of the CS polymer. ${ }^{43}$ The other possible explanation for the smaller particle size recorded by TEM analysis is that, at lower acidic conditions ( $\mathrm{pH} \sim 5-6)$, more amine and carboxylate groups from CS chain that are readily made available for bonding with the $\mathrm{Zn}$ ions, thus acting as electron donors, which reduces the electrostatic
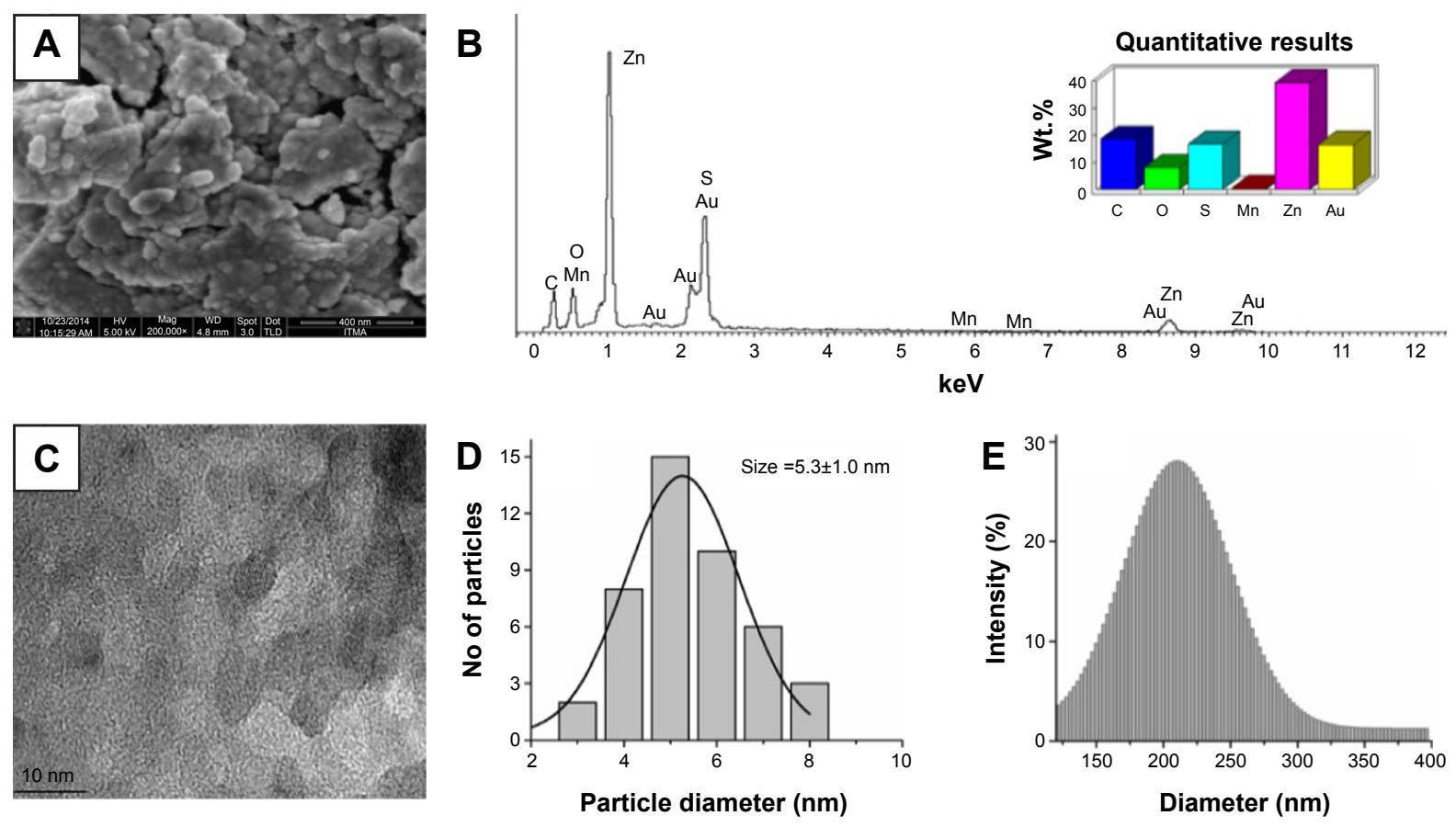

Figure 2 FACS-Mn:ZnS analysis by means of FESEM (A), EDAX spectrum with inset showing the percentage elemental composition (B), HRTEM (C), particle size distribution from HRTEM (D), and DLS-analyzed hydrodynamic size distribution (E).

Abbreviations: DLS, dynamic light scattering; EDAX, energy dispersive analysis X-ray; FACS-Mn:ZnS, folic acid-chitosan stabilized Mn²-doped ZnS; FESEM, field emission scanning electron microscopy; HRTEM, high-resolution transmission electron microscopy; ZnS, zinc sulfate. 
repulsion and thereby favoring the stabilization of $\mathrm{Mn}: \mathrm{ZnS}$ nanocrystals to a more smaller and compact dimensions. ${ }^{44}$ Thus from the cumulative analysis, the maximum particle size recorded for FACS-Mn:ZnS in both the solution phase (DLS, $\sim 200 \mathrm{~nm})$ and powder form $(\sim 5.3 \mathrm{~nm})$ still falls within nanometer range.

The elemental analysis of FACS-Mn:ZnS QDs following XPS and XRF analyses are shown in Figure 3A-E and Table 1, respectively. Figure $3 \mathrm{~A}$ shows the comparison of XPS scanned surveys of FACS-Mn:ZnS composite and bare $\mathrm{Mn}: \mathrm{ZnS}$ QDs of which both were prepared with 15 at.\% of $\mathrm{Mn}^{2+}$ doping. One can see from the spectra that, only the peaks of $\mathrm{Zn}, \mathrm{S}, \mathrm{Mn}, \mathrm{O}$, and $\mathrm{C}$ are vividly appeared and when compared with bare Mn:ZnS QDs, a small peak corresponding to nitrogen $(\mathrm{N})$ appearing only in the survey analysis of FACS-Mn:ZnS, providing the information about the conjugation of FA and CS molecules. Further in Figure 3B, the peak of Zn 2p3/2 appeared at 1,021 eV for the bare Mn:ZnS and 1,020 eV for FACS-Mn:ZnS confirming the existence of $\mathrm{Zn}$ largely as $\mathrm{Zn}^{2+}$ linked to a sulfur atom. The binding energies of $\mathrm{Zn} 2$ p3/2 and S 2 p were only weakly affected by the conjugation of Mn:ZnS with FACS showing a shift of $\sim 1 \mathrm{eV}$ when conjugated with CS and FA. We also observed a very weak peak for Mn 2p3/2 centered at 640 and $639 \mathrm{eV}$ on conjugating with FACS as represented in Figure $3 \mathrm{C}$. The observation of a weak peak can be due to the low concentration of Mn element at the surface of the QDs, a similar phenomenon was reported by some researchers following the doping of $\mathrm{Mn}$ on $\mathrm{ZnS}$ nanocrystals. ${ }^{45,46}$

Figure 3D shows the peak of S 2p3/2, where the spectra for bare Mn:ZnS QDs has its peak centered at $162 \mathrm{eV}$, while the peak shifted to $160 \mathrm{eV}$ on conjugation with FACS. Following the anchorage of Mn:ZnS QDs with CS and FA, the XPS spectrum showed a signal of $\mathrm{N} 1 \mathrm{~s}$ corresponding to the nitrogen atom from the amine groups of either the FA or CS (Figure 3E). The presence of elements in the composite was further substantiated from the XRF results shown in Table 1, approximately $80 \%$ and $13 \%$ corresponding to $\mathrm{Zn}$ and S, respectively was recorded. However, it has been reported by some researchers that the actual concentration of $\mathrm{Mn}^{2+}$ (at.\%) incorporated into the host $\mathrm{ZnS}$ is quiet less than the amount used during the synthesis. Kole et $\mathrm{al}^{10}$ using electron probe microanalyzer reported that the optimum amount of $\mathrm{Mn}^{2+}$ concentration of 1.10 (at.\%) corresponded to 40.0 (molar \%) concentrations used during the synthesis. As a consequence of these observations, inductively coupled plasma-optical emission spectrometry analysis was used by some researchers to determine the actual concentration of
$\mathrm{Mn}^{2+}$. In their study, Kole et al used 1 and 5 at. $\%$ of $\mathrm{Mn}^{2+}$ with respect to $\mathrm{Zn}^{2+}$ during the synthesis, but from the outcome of the analysis, the actual concentration of the $\mathrm{Mn}^{2+}$ incorporated into the final product was found to be 0.04 at.\% for 1 at. $\%$ used and 0.18 at. $\%$ for 5 at. $\%$ used during the synthesis. ${ }^{10}$ These findings provide a proof for the observation of only trace amounts of $\mathrm{Mn}^{2+}$ recorded by EDAX, XPS, and XRF analysis in our study.

Figure 4A-C shows the powdered XRD pattern, thermal analysis, and FTIR spectrums of Mn:ZnS before and after conjugation with FACS, respectively. The pattern in Figure $4 \mathrm{~A}$ indicates the formation of $\mathrm{ZnS}$ in a cubic blend (sphalerite) structure by the observation of peaks at $28.46^{\circ}$, $48.16^{\circ}$, and $55.28^{\circ}$ corresponding to prominent diffraction at (111), (220), and (311), respectively. The pattern shows no lattice distortion of the presence of $\mathrm{Mn}^{2+}$ impurities or any differentiated lattice structure with that of $\mathrm{Zn}^{2+}$. One probable reason can be a result of the similarity in the oxidation state and ionic radii of $\mathrm{Mn}^{2+}$ with that of $\mathrm{Zn}^{2+}$, in addition to the lower concentration of $\mathrm{Mn}$. However, a slight reduction in the peak intensity of FACS-Mn:ZnS is observed probably due to the complete coverage of Mn:ZnS QDs with that of $\mathrm{CS}$ and FA molecules. The thermal analysis studied for CS, $\mathrm{Mn}: \mathrm{ZnS}$, and FACS-Mn:ZnS recorded in the temperature range of up to $600^{\circ} \mathrm{C}$ (Figure 4B) indicates the stability of $\mathrm{Mn}: \mathrm{ZnS}$ composite due to its conjugation with FA and CS. From the TGA graph for pure CS, two curves are observed; the observation of the first curve below $200^{\circ} \mathrm{C}$ temperature can be attributed to the moisture loss from the sample, while the second curve around $230^{\circ} \mathrm{C}$ is due to the decarboxylation of $\mathrm{COO}^{-}$groups. Also, the graph of $\mathrm{Mn}: \mathrm{ZnS}$ sample has some weight loss during $60^{\circ} \mathrm{C}-150^{\circ} \mathrm{C}$ and this loss can be attributed to the evaporation of occluded moisture adsorbed at the surface of the particles. The particles displayed thermal stability after $300^{\circ} \mathrm{C}$ up to $600^{\circ} \mathrm{C}$ and finally left with around $50 \%$ of its initial weight. As similar to the other curves, the TGA curve of FACS-Mn:ZnS shows a drop in weight from $50^{\circ} \mathrm{C}$ to $120^{\circ} \mathrm{C}$ due to the moisture loss and a slight depression during $150^{\circ} \mathrm{C}-450^{\circ} \mathrm{C}$ either from the decarboxylation of the carboxylate groups or from loss of $\mathrm{CO}_{2}$. The observation of thermal stability in accordance with bare $\mathrm{Mn}: \mathrm{ZnS}$ in the temperature range of $450^{\circ} \mathrm{C}-600^{\circ} \mathrm{C}$ is an indication for the persistence of $\mathrm{Mn}^{2+}$ and $\mathrm{Zn}^{2+}$ ions in the composite. Furthermore, the thermal behavior of FACS-Mn:ZnS composite at $600^{\circ} \mathrm{C}$ remaining with the highest weight of $70 \%$ as compared with the other two samples serves as a proof for the applicability of the concept of polymer composite formation to nanomaterials. 

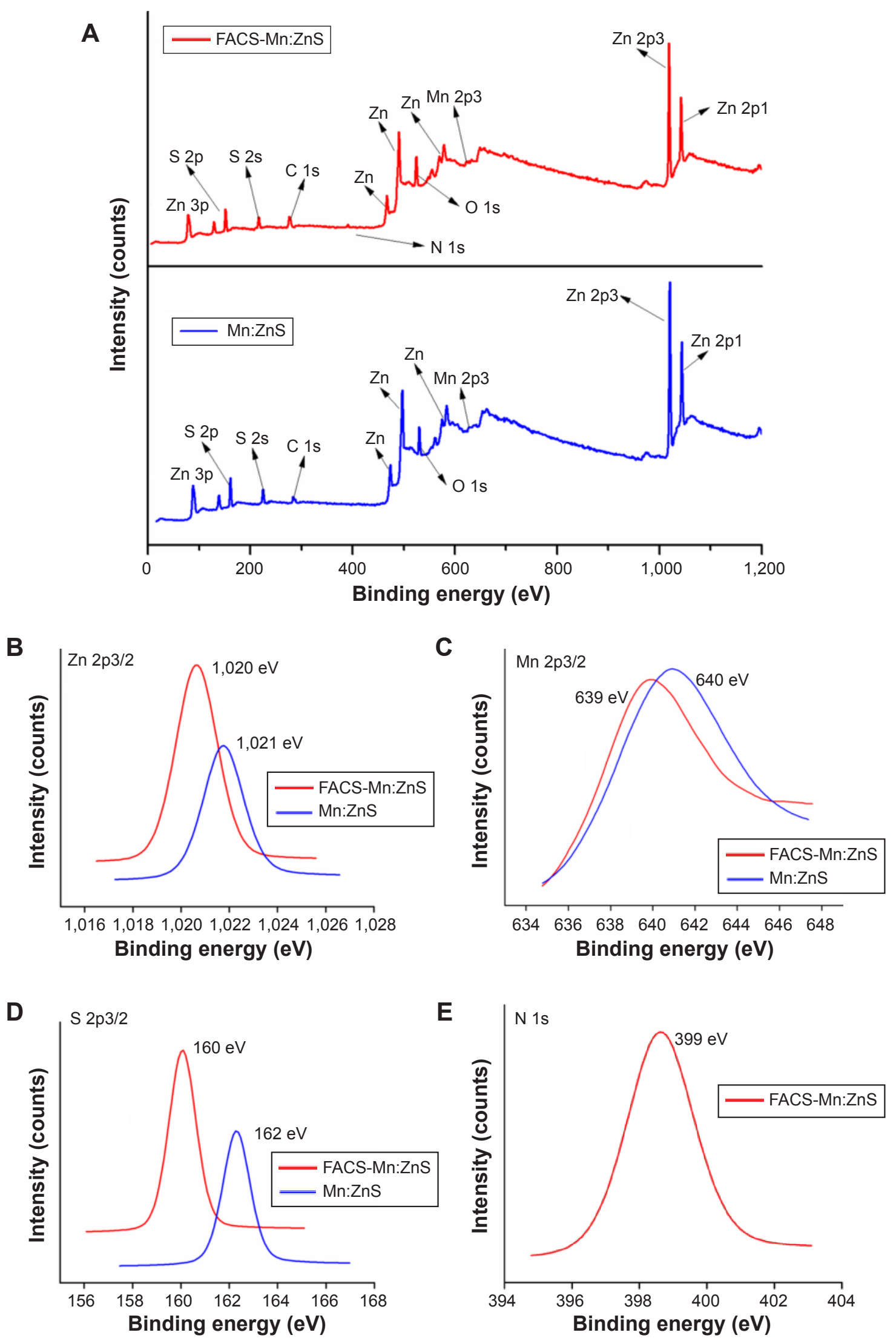

Figure 3 Comparison of the XPS data for Mn:ZnS and FACS-Mn:ZnS QDs showing (A) total survey, (B) Zn 2p3/2, (C) Mn 2p3/2, (D) S 2p3/2, and (E) N Is (only for FACS$\mathrm{Mn}: \mathrm{ZnS})$ elements.

Abbreviations: FACS-Mn:ZnS, folic acid-chitosan stabilized $\mathrm{Mn}^{2+}$-doped ZnS; XPS, X-ray photoelectron spectroscopy; QDs, quantum dots. 
Table I Comparison of the XRF-analyzed elemental composition of FACS-Mn:ZnS (at various at.\%) and bare Mn:ZnS QDs

\begin{tabular}{lllll}
\hline Element & FACS-Mn:ZnS & FACS-Mn:ZnS & FACS-Mn:ZnS & $\begin{array}{l}\text { Mn:ZnS } \\
\text { (5 at.\%) }\end{array}$ \\
\hline$Z n$ & $(\mathbf{I}$ at.\%) & $(\mathbf{1 0}$ at.\%) & 89.549 & 85.784 \\
$S$ & 85.374 & 87.443 & 10.218 & 13.681 \\
Mn & 13.962 & 12.104 & 0.233 & 0.531 \\
\hline
\end{tabular}

Abbreviations: FA, folic acid; CS, chitosan; QDs, quantum dots; XRF, X-ray fluorescence.

The comparison of FTIR spectra of FACS-Mn:ZnS composite with that of bare Mn:ZnS, FA, and CS are shown in Figure 4C. For the as-synthesized bare $\mathrm{Mn}: \mathrm{ZnS}$, the characteristic absorption bands originated largely from $\mathrm{Zn}-\mathrm{S}-\mathrm{Mn}$ bonds only. Also, the observation of a broad band in the bare $\mathrm{Mn}: \mathrm{ZnS}$ sample at 3,254 $\mathrm{cm}^{-1}$ corresponds to the stretching vibration of hydroxyl $(\mathrm{O}-\mathrm{H})$ group from the occluded water absorbed by the crystals; similar vibration mode was also observed at 3,284 $\mathrm{cm}^{-1}$ in the FACS-Mn:ZnS composite too. The two silent peaks at 2,358 and 2,166 $\mathrm{cm}^{-1}$ can be due to $\mathrm{Zn}-\mathrm{S}$ microstructure vibration and from $\mathrm{CO}$ stretching vibrations, respectively. The $\mathrm{Zn}-\mathrm{S}$ vibration peak (at 2,358 $\mathrm{cm}^{-1}$ ) observed in Mn:ZnS is not pronounced in the spectra of FACS-Mn:ZnS and can be attributed to the interaction between the $\mathrm{Zn}-\mathrm{S}$ and the carboxylate groups of FA or CS. The peaks at 1,406 and $1,544 \mathrm{~cm}^{-1}$ in the spectra of $\mathrm{Mn}: \mathrm{ZnS}$
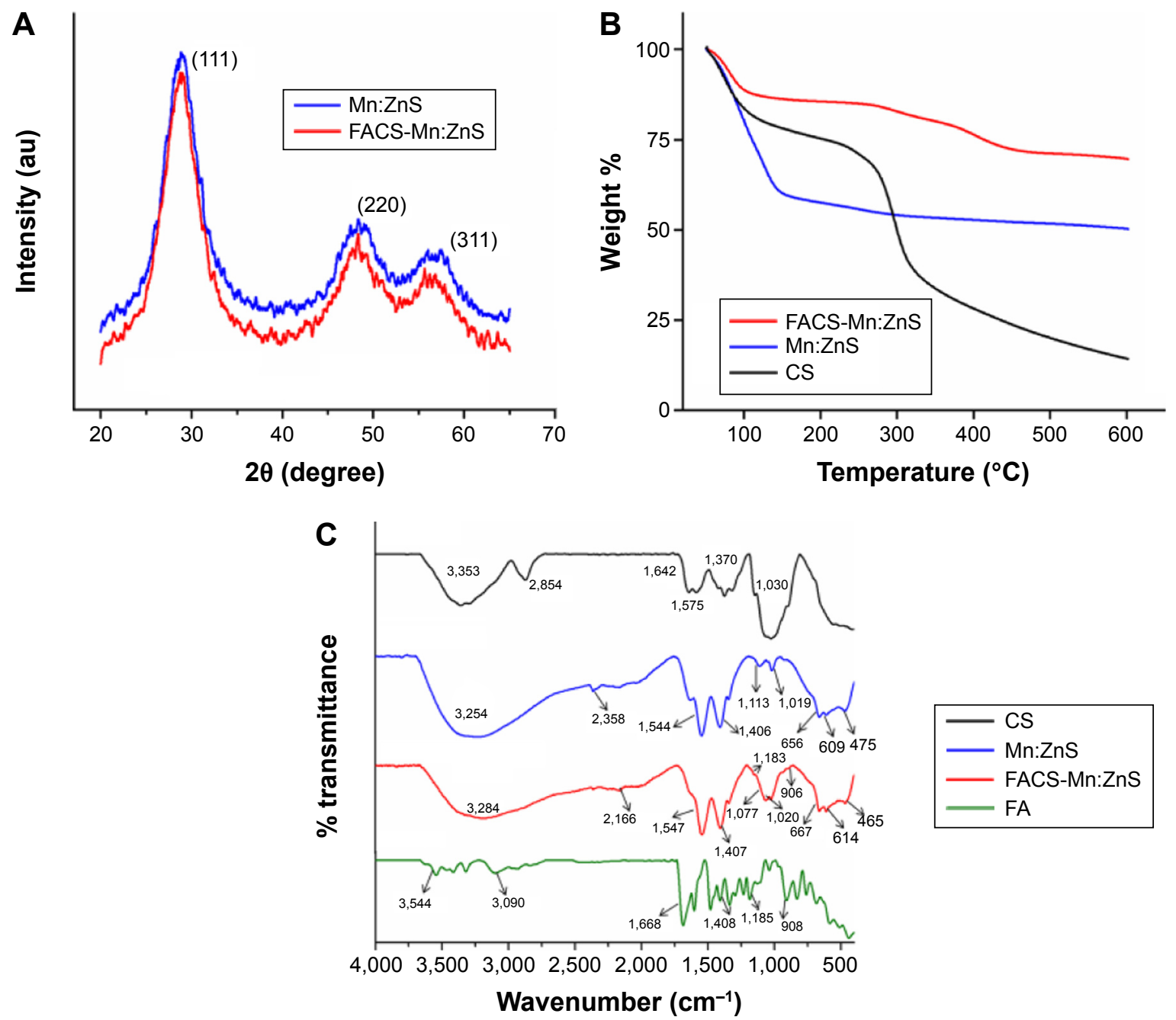

Figure 4 Comparison of FACS-Mn:ZnS and bare Mn:ZnS QDs by means of powdered XRD patterns (A), TGA in the temperature range of up to $600^{\circ} \mathrm{C}$ (B), and FTIR spectral analysis (C).

Abbreviations: CS, chitosan; FA, folic acid; FACS-Mn:ZnS, folic acid-chitosan stabilized Mn²-doped ZnS; FTIR, Fourier transform infrared; TGA, thioglycolic acid; XRD, X-ray diffraction; QDs, quantum dots. 
can be assigned to the symmetric and asymmetric stretching of $\mathrm{COO}^{-}$, respectively, while the peak at $1,113 \mathrm{~cm}^{-1}$ corresponds to the symmetric stretching vibration of $\mathrm{Zn}-\mathrm{S}-\mathrm{Mn}$ bond. This peak is however not visible in the spectra of FACS-Mn:ZnS probably due to the masking of $\mathrm{C}-\mathrm{O}-\mathrm{C}$ stretching vibrations of peak at $1,077 \mathrm{~cm}^{-1}$ on CS's peak (at $1,030 \mathrm{~cm}^{-1}$ ). This can also be the reason for the observation of a shifted peak at $1,019 \mathrm{~cm}^{-1}$ in the spectra of $\mathrm{Mn}: \mathrm{ZnS}$ to $1,020 \mathrm{~cm}^{-1}$ as seen in the spectra of FACS-Mn:ZnS. The small peaks at 906 and $1,183 \mathrm{~cm}^{-1}$ in the spectra of FACS$\mathrm{Mn}: \mathrm{ZnS}$ can be from the aromatic $\mathrm{C}-\mathrm{H}$ out-of-plan bending of FA $\left(908 \mathrm{~cm}^{-1}\right)$ and $\mathrm{C}-\mathrm{N}$ stretching vibration from FA $\left(1,185 \mathrm{~cm}^{-1}\right)$. Both samples shows $\mathrm{ZnS}$ band and symmetric bending due to $\mathrm{Zn}-\mathrm{S}$ or $\mathrm{Mn}-\mathrm{S}$ vibrations at 656 and $609 \mathrm{~cm}^{-1}$ for $\mathrm{Mn}: \mathrm{ZnS}$ and 667 and $614 \mathrm{~cm}^{-1}$ in the spectra of FACS$\mathrm{Mn}: \mathrm{ZnS}$, respectively. Similarly, the peaks at $475 \mathrm{~cm}^{-1}$ in the spectra of Mn:ZnS and $465 \mathrm{~cm}^{-1}$ for FACS-Mn:ZnS can be due to $\mathrm{S}-\mathrm{S}$ or $\mathrm{Mn}-\mathrm{O}$ or $\mathrm{S}-\mathrm{O}$ interactions.

The comparison of UV-Vis absorption spectra of FA, bare Mn:ZnS, and FACS-Mn:ZnS QDs is shown in Figure 5A and the Tauc plot in Figure 5B. As shown in the Figure 5A, the absorption of FA is observed at $280 \mathrm{~nm}$, while the bare Mn:ZnS has absorption onset at $328 \mathrm{~nm}$ and FACS-Mn:ZnS at $318 \mathrm{~nm}$. From the spectra, the optical absorption properties of the synthesized FACS-Mn:ZnS shows an absorption peak that is slightly red shifted from the absorption band edge of bulk ZnS QDs (at $334 \mathrm{~nm}$ ) owing to quantum confinement effects $^{47}$ and following the doping of host $\mathrm{ZnS}$ with $\mathrm{Mn}^{2+}$ impurities. ${ }^{48}$ Figure 5B shows the Tauc plot of $(\alpha h v)^{2}$ versus $(h v)$ from the UV-Vis spectra and by extrapolation of the linear part of the curve to the energy axis based on Equation 1, the band gap energy of our sample ( $E g)$ FACS-Mn:ZnS QDs was calculated to be $5.08 \mathrm{eV}$, a blue shift of approximately $1.4 \mathrm{eV}$ from the band gap energy of bulk $\mathrm{ZnS}$ taking from literature value, ${ }^{10}$

$$
\alpha h v=B(h v-E g) \frac{1}{2}
$$

where $\alpha$ is the absorption coefficient, $h v$ is the photon energy, $E g$ is the direct band gap energy, and $B$ is a constant.

The Mn:ZnS QD's characteristic fluorescence behavior and its mechanism at various stages is fully demonstrated in Figure 6A-C. The Figure 6A shows the comparison of fluorescence spectra of bare $\mathrm{ZnS}$ QDs (without Mn doping) and FACS-Mn:ZnS (with Mn doping). The fluorescence comparison of the two samples provides the information that the doping of $\mathrm{ZnS}$ QDs with suitable impurity such as $\mathrm{Mn}^{2+}$ and independent of particle size can significantly enhance its luminescence properties. As seen from the spectra, the doping of $\mathrm{ZnS}$ with $\mathrm{Mn}^{2+}$ induces a red shift from the blue region at $450 \mathrm{~nm}$, typical of undoped $\mathrm{ZnS}$ to more biofriendly visible region. The characteristic $\mathrm{ZnS}$ spectral shifted from the blue region toward the red region on doping with $\mathrm{Mn}^{2+}$ impurities and resulted in the emission of orange fluorescence at $600 \mathrm{~nm}$. Similarly, Figure 6B shows what actually transpired following the doping chemistry, a change in color to orange when viewed under handheld UV lamp. From the Jaboliski diagram shown in Figure 6C, several mechanisms interplay to produce fluorescence emission in QDs following the excitation of ground state electron to the excitonic state. The excited electrons either radiatively or nonradiatively relax and in the process, they recombine with the holes in the ground state with the emission of
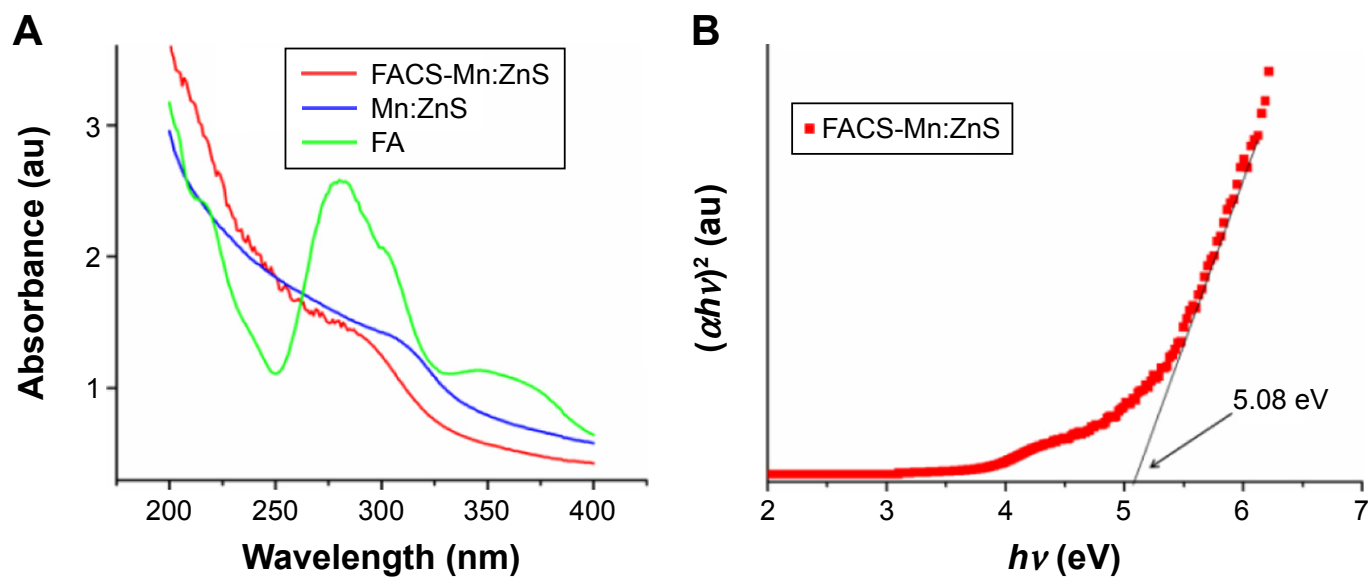

Figure 5 (A) Comparison of the UV-Vis spectra of FA with that of bare Mn:ZnS and FACS-Mn:ZnS QDs; (B) Tauc plot obtained from the UV-Vis study with a band gap energy of $5.08 \mathrm{eV}$ for FACS-Mn:ZnS QDs.

Abbreviations: FA, folic acid; FACS-Mn:ZnS, folic acid-chitosan stabilized Mn²+-doped ZnS; QDs, quantum dots; UV-Vis, ultraviolet-visible; ZnS, zinc sulfate. 

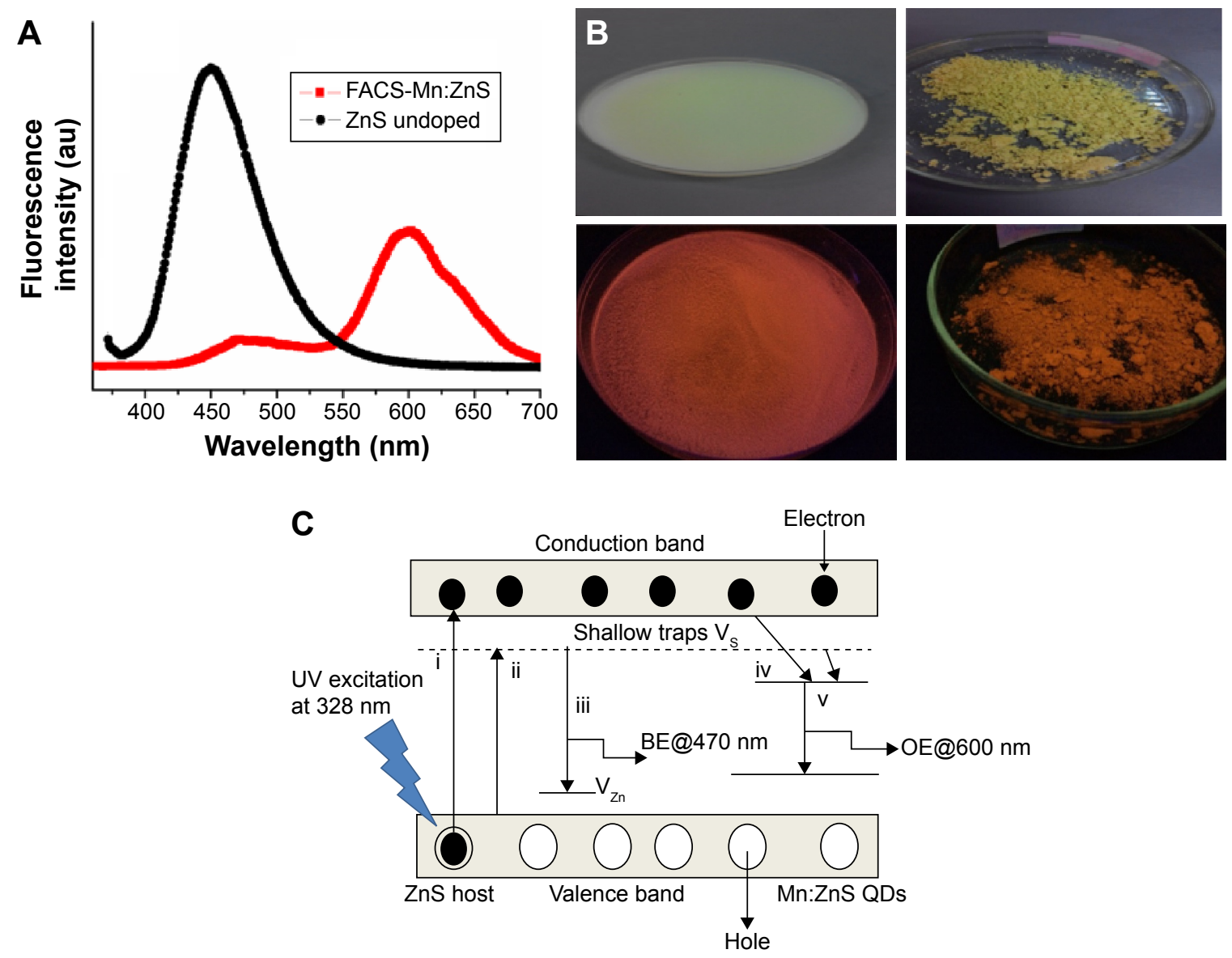

Figure 6 (A) Fluorescence emission spectra of undoped ZnS QDs and Mn²+doped ZnS QDs. (B) Various color changes generated by the FACS-Mn:ZnS QDs, top two images (solution and pellet) under day light and bottom two images (solution and pellet) under handheld UV lamp. (C) Fluorescence mechanism of FACS-Mn:ZnS QDs, (i) photon absorption and excitation, (ii) interstitial energy levels involving sulfur and zinc emissions, (iii) BE from $\mathrm{Zn}$ and $\mathrm{S}$ relaxation energy state, (iv) interstitial energy trapped by $\mathrm{Mn}$ ions in $\mathrm{d}$ state, and (v) OE due to $\mathrm{Mn}^{2+}$ luminescence center.

Abbreviations: BE, blue emission; FACS-Mn:ZnS, folic acid-chitosan stabilized $\mathrm{Mn}^{2+}$-doped ZnS; QDs, quantum dots; UV, ultraviolet; OE, orange emission.

fluorescence light. In the case of $\mathrm{ZnS}$ as diagrammatically represented, the electron in the conduction band (CB) of $\mathrm{ZnS}$ lattice radiatively relaxes to the hole in the valence band (VB) passing through interstitial pathways of sulfur $\left(\mathrm{I}_{\mathrm{s}}\right)$ and $\mathrm{Zn}\left(\mathrm{I}_{\mathrm{z}}\right)$. The emission at $470 \mathrm{~nm}$ is due to the relaxation that occurs when the excited state electrons are trapped by sulfur vacancy donor levels. ${ }^{49,50} \mathrm{The}^{\mathrm{Mn}^{2+}}$ ion has a $\mathrm{d}^{5}$ configuration, where the d-electron state plays a central role as the luminescence center by interacting strongly with the $s-p$ electronic state of the host $\mathrm{ZnS}$ in response to the electronic excitation. ${ }^{10}$ The resultant transfer of electrons and holes charges into the electronic level of $\mathrm{Mn}^{2+}$ ions allow the emission of characteristic orange-red fluorescence following ${ }^{4} \mathrm{~T}_{1}{ }^{-} \mathrm{A}_{1}$ transition of the $\mathrm{Mn}^{2+}$ ion. ${ }^{10}$ To further buttress the phenomenon surrounding the effect of doping of atoms to $\mathrm{ZnS}$, several pathways are reported to take part during the excitation of $\mathrm{Mn}^{2+}$ in the host $\mathrm{ZnS}$ and the subsequent orange emission (OE). As can be seen in Figure 6C, three main possible pathways maybe responsible for the electronhole recombination that further leads to $\mathrm{OE}::^{50}$

1. In the first relaxation pathway, there exists the possibility that the electron in the $\mathrm{CB}$ of the $\mathrm{ZnS}$ lattice radiatively relaxes to the holes in the VB through $\mathrm{I}_{\mathrm{s}}$ and $\mathrm{I}_{\mathrm{z}}$ (ie, interstitial sites of sulfur and zinc). Due to lattice strain induced by $I_{s}$ and the large ionic radius of sulfur ion as compared with $\mathrm{Zn}$ ions, the electrons initiated by $\mathrm{I}_{\mathrm{s}}$ has small binding energy relative to $\mathrm{Zn}$ ion. ${ }^{49}$

2. In the second relaxation pathway, it is possible that the blue emission can be observed at $475 \mathrm{~nm}$ from the relaxation that occurs when the electrons in the excited state are trapped by the sulfur vacancy donor levels.

3. It is further considered that: a) the excited electrons trapped by the sulfur vacancy level can nonradiatively relax to the ${ }^{4} \mathrm{~T}_{1}$ level of $\mathrm{Mn}^{2+}$; and $\mathrm{b}$ ) the electrons in the excited state may directly relax to the ${ }^{4} \mathrm{~T}_{1}$ level of $\mathrm{Mn}^{2+}$ by nonradiative transition. As previously mentioned, the 
electrons generated at ${ }^{4} \mathrm{~T}_{1}$ level of $\mathrm{Mn}^{2+}$ following either of the possible paths can recombine radiatively with the holes trapped in the ground state $\left({ }^{6} \mathrm{~A}_{1}\right)$ of $\mathrm{Mn}^{2+}$ ions; this accounts for the OE recorded in our study at $\sim 600 \mathrm{~nm}$. The fluorescence emission at the visible and far red is more intense than the blue emission regions. One possible reason can be due to the nonradiative transition of electrons from the $\mathrm{CB}$ to the ${ }^{4} \mathrm{~T}_{1}$ level of the $\mathrm{Mn}^{2+}$ ions is much faster than the electron captured by the sulfur vacancy level. ${ }^{51}$

The comparison of fluorescence behavior of FACS$\mathrm{Mn}: Z n S$ QDs as against the changes in the physical parameters such as UV light, $\mathrm{pH}$, and dopant concentration are shown in Figure 7A-D. From the comparison of fluorescence spectra shown in Figure 7A and B, there is a possibility of unwanted relaxation pathways recombining to produce the
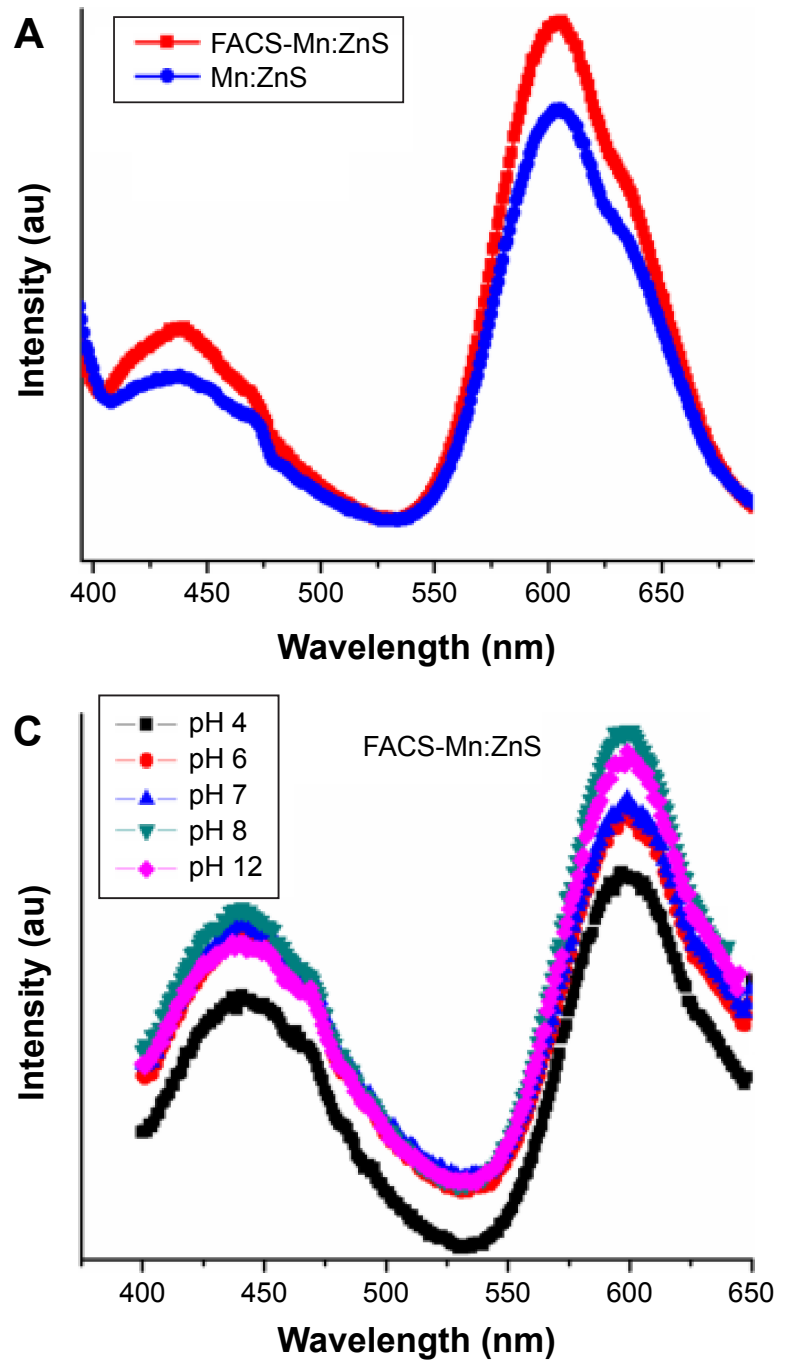

defect curve observed between 400 and $470 \mathrm{~nm}$ regions. This characteristic phenomenon was observed to be more pronounced on the synthesized samples in the absence of UV irradiation (Figure 7A) and however observed to be milder on samples treated under UV irradiation (Figure 7B). The treatment of QDs with UV irradiation being used by most researchers to enhance the luminescence center of $\mathrm{Mn}^{2+}$ doped $\mathrm{ZnS}$ suppresses the activity of unwanted nonradiative recombination. ${ }^{10-12}$ However, from the spectra, after treatment with UV irradiation, we expect a significant rise in the fluorescence intensity but on the contrary, a drop in intensity was recorded for FACS-Mn:ZnS. One possible conclusion is that, the polymer conjugated to the QDs may induce a restriction of the rotational motion of dipole molecules and immobilization of the electron-hole charge ions, thereby interfering with the surface chemistry. ${ }^{52,53}$ Geszke et al ${ }^{44}$ reported two
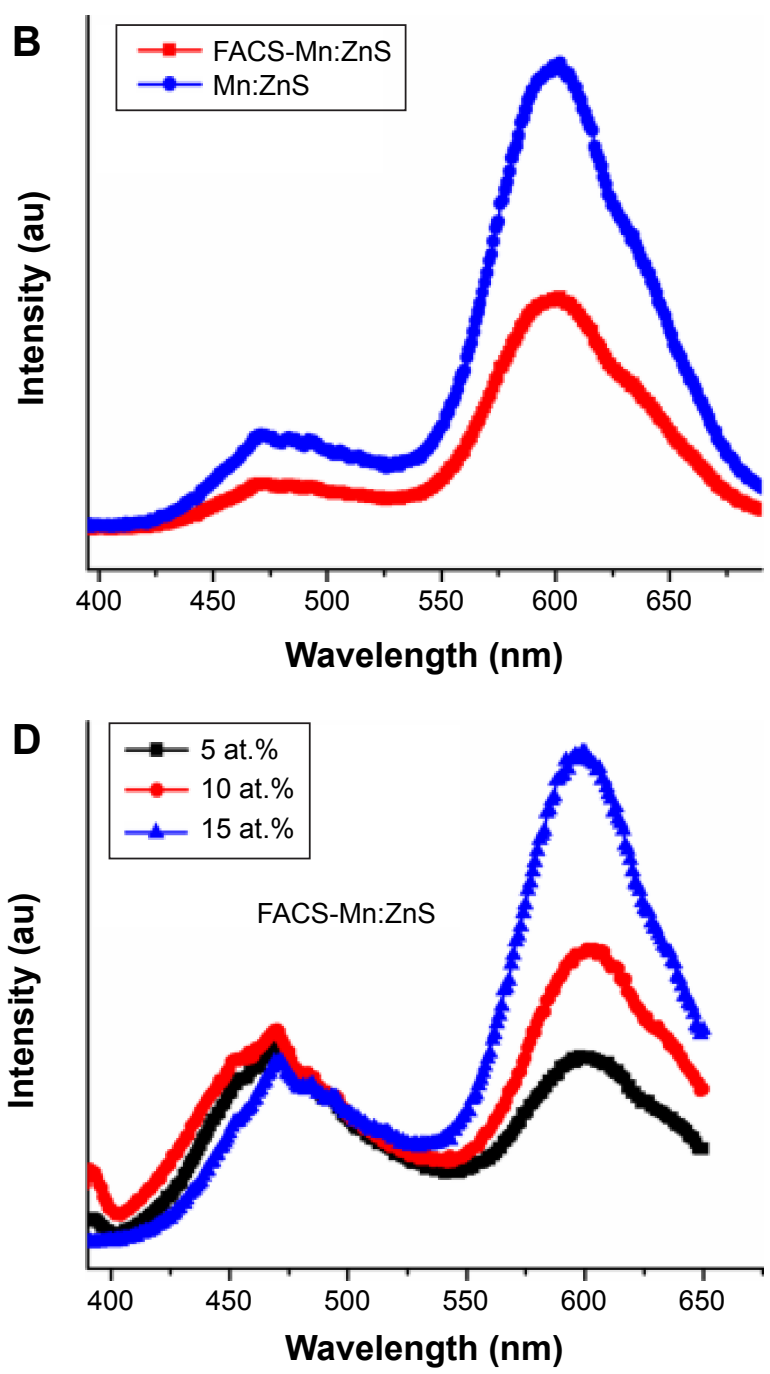

Figure 7 Comparison of the fluorescence behavior of Mn:ZnS and FACS-Mn:ZnS QDs in the absence (A) and in the presence (B) of UV irradiation. Fluorescence efficiency is represented as against changes in $\mathrm{pH}(\mathbf{C})$ and dopant concentration (D).

Abbreviations: FACS-Mn:ZnS, folic acid-chitosan stabilized $\mathrm{Mn}^{2+}$-doped ZnS; QDs, quantum dots; UV, ultraviolet; ZnS, zinc sulfate. 
possible mechanisms as reason for the observed quenching effects: 1) the FA conjugated to the QDs can interfere and trap part of the excitation light intensity driven by collisions between FA and QDs; and 2) FA readily conjugate to $\mathrm{Mn}: \mathrm{ZnS}$ through the carboxylate groups or through the nitrogen atoms. Following this strong affinity toward each other, there exists the possibility that the highest occupied molecular orbital and lowest unoccupied molecular orbital of the FA overlap with the $\mathrm{CBs}$ of $\mathrm{Zn}^{2+}\left(4 \mathrm{~s}^{0}\right)$ initiating energy transfer from the Mn:ZnS to the FA. In order to reduce the quenching effect as a result of the conjugation of the QDs with FA, they observed and reported in their experiment that the luminescence intensity of QDs was only weakly altered $(\sim 5 \%)$ when the concentration at molar ratios of FA:QDs was maintained near to 0.01 .

The fluorescence intensity behavior measured as against the changes in external factors such as $\mathrm{pH}$ (Figure 7C) and dopant ion concentration (Figure 7D) indicates that they both have significant influence toward the fluorescence efficiency. As seen from the comparison of spectra (Figure 7C), the fluorescence intensity increases from $\mathrm{pH} 4$ to 8 and it drops from pH 12 to a level below pH 8. From the observed pattern, due to higher acidic environment at $\mathrm{pH} 4$, there is a possibility for the dissociation of carboxylate or amino groups present at the surface of QDs and thereby distorting the coordination. Also, the high alkaline environment at $\mathrm{pH} 12$ favors the formation of metal oxides or hydroxides as a result of the presence of large number of $\mathrm{OH}$ ions. Based on the observed pattern, fluorescence efficiency was recorded to be more stable at low acidic and low alkaline $\mathrm{pH}$ (ie, $\mathrm{pH}$ around 6-8). Similarly, the changes in spectra from blue to visible region on doping of $\mathrm{ZnS}$ with $\mathrm{Mn}^{2+}$ were also observed to increase following an increase in the concentration of $\mathrm{Mn}^{2+}$ (Figure 7D).

The comparison of cell viability and proliferation studies following the treatment of $\mathrm{Mn}: \mathrm{ZnS}$ and FACS-Mn: $\mathrm{ZnS}$ as against different cell lines are shown in Figure 8A-D.
A
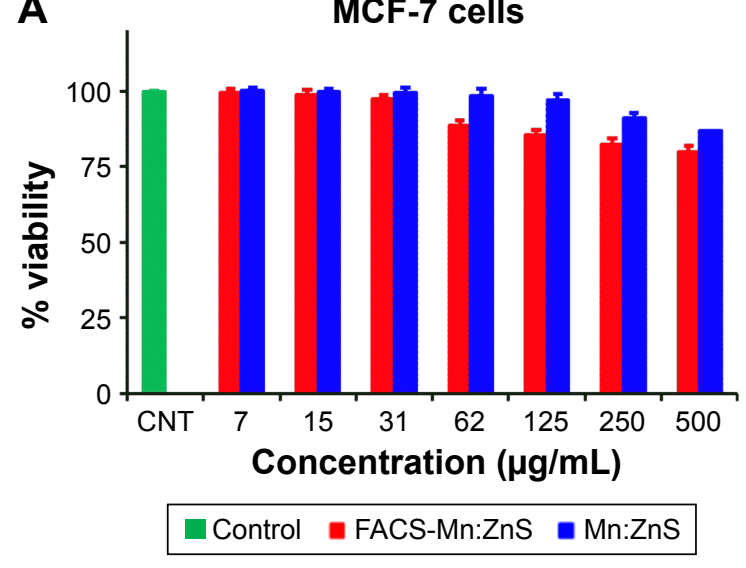

C

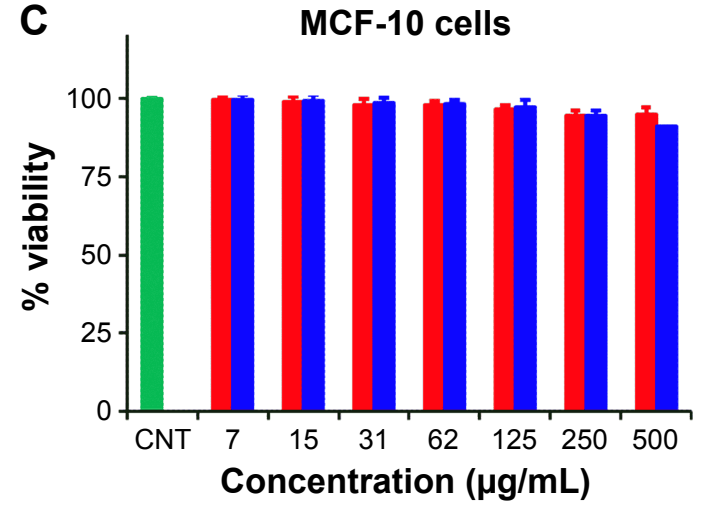

Control $\square$ FACS-Mn:ZnS $\square \mathrm{Mn}: \mathrm{ZnS}$
B

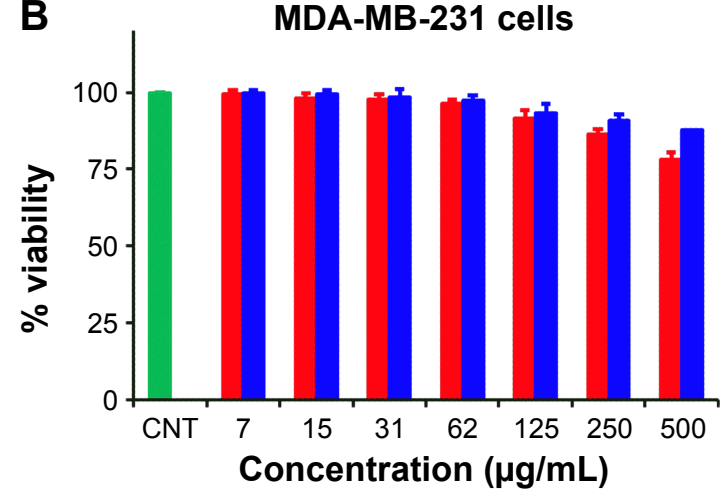

Control $\backsim$ FACS-Mn:ZnS $\square \mathrm{Mn}: \mathrm{ZnS}$

D

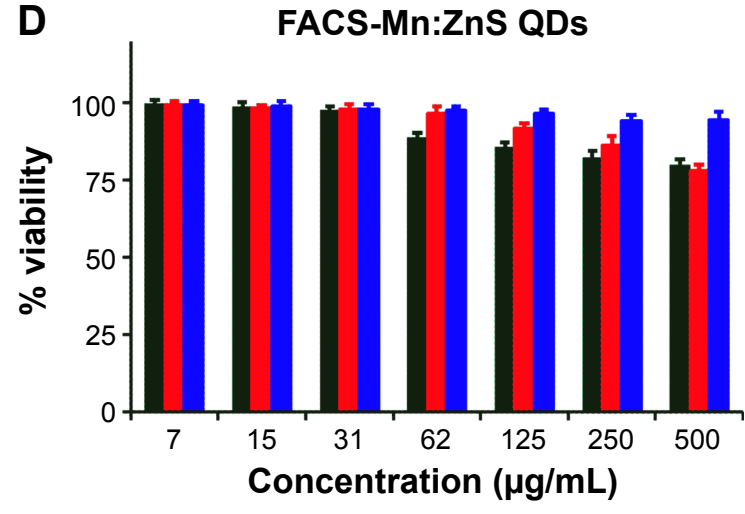

MCF-7 MDA-MB-231 MCF-10

Figure 8 Comparison of the cell viability effects between Mn:ZnS and FACS-Mn:ZnS QDs toward (A) MCF-7 cells, (B) MDA-MB-23I cells, and (C) MCF-I0 cells lines. The comparison of cell viability effects of all the three cell lines toward FACS-Mn:ZnS QDs is shown in (D).

Note: The data shown are the mean \pm standard deviation of three individual experiments.

Abbreviations: FACS-Mn:ZnS, folic acid-chitosan stabilized $\mathrm{Mn}^{2+}$-doped ZnS; QDs, quantum dots; ZnS, zinc sulfate; CNT, control. 
The MTT assay was performed on two breast cancer cell lines, MCF-7 (Figure 8A), MDA-MB-231 (Figure 8B), and normal human breast cell line (MCF-10, Figure 8C) grown for 24 hours with medium containing bare $\mathrm{Mn}: \mathrm{ZnS}$ QDs and FACS-Mn:ZnS with concentrations ranging from 7 to $500 \mu \mathrm{g} / \mathrm{mL}$. From the comparative analysis of the cells cultured without the composites as control, the results demonstrated that the QDs did not exhibit discernable adverse effects in vitro in all the cell lines. The results show only a slight reduction in the cells viability in response to an increase in QDs concentrations, especially pronounced from 62 to $500 \mu \mathrm{g} / \mathrm{mL}$ on cells treated with FACS-Mn:ZnS as compared with those exposed to bare Mn:ZnS QDs. One possible reason for this slight reduction in cells viability for the cells treated with FACS-Mn:ZnS can be due to the enhanced cellular binding interactions between the conjugated FA-containing QDs with the FR-expressed cancer cells. These relationships were further substantiated when comparing the MTT result of normal breast cell line (MCF-10) with that of cancer breast cells (MCF-7 and MDA-MB-231) treated with FACS$\mathrm{Mn}: \mathrm{ZnS}$ (Figure 8D). From the result, the reduction in cells viability was observed to be more pronounced on cells expressing FRs (MCF-7 and MDA-MB-231) as compared with the normal cells without FRs (MCF-10), suggesting that the expression of FRs on cancerous cells enhances the intracellular concentrations of QDs conjugated with FA.

The in vitro fluorescence imaging studies conducted on human breast cancer lines (MCF-7 and MDA-MB-231) that expressed FRs and normal breast cells (MCF-10) without FRs are shown in Figure 9A-D. From the figure, it can be seen that the composite conjugated with FA demonstrated specific attachment by emitting out cellular fluorescence from the QDs attached to the FRs expressed on the cancer cells (Figure 9B-iii and C-iii). However, just the milder fluorescence effects were observed on cells administered with nonconjugated FA composites (Mn:ZnS, Figure 9A-iii) and

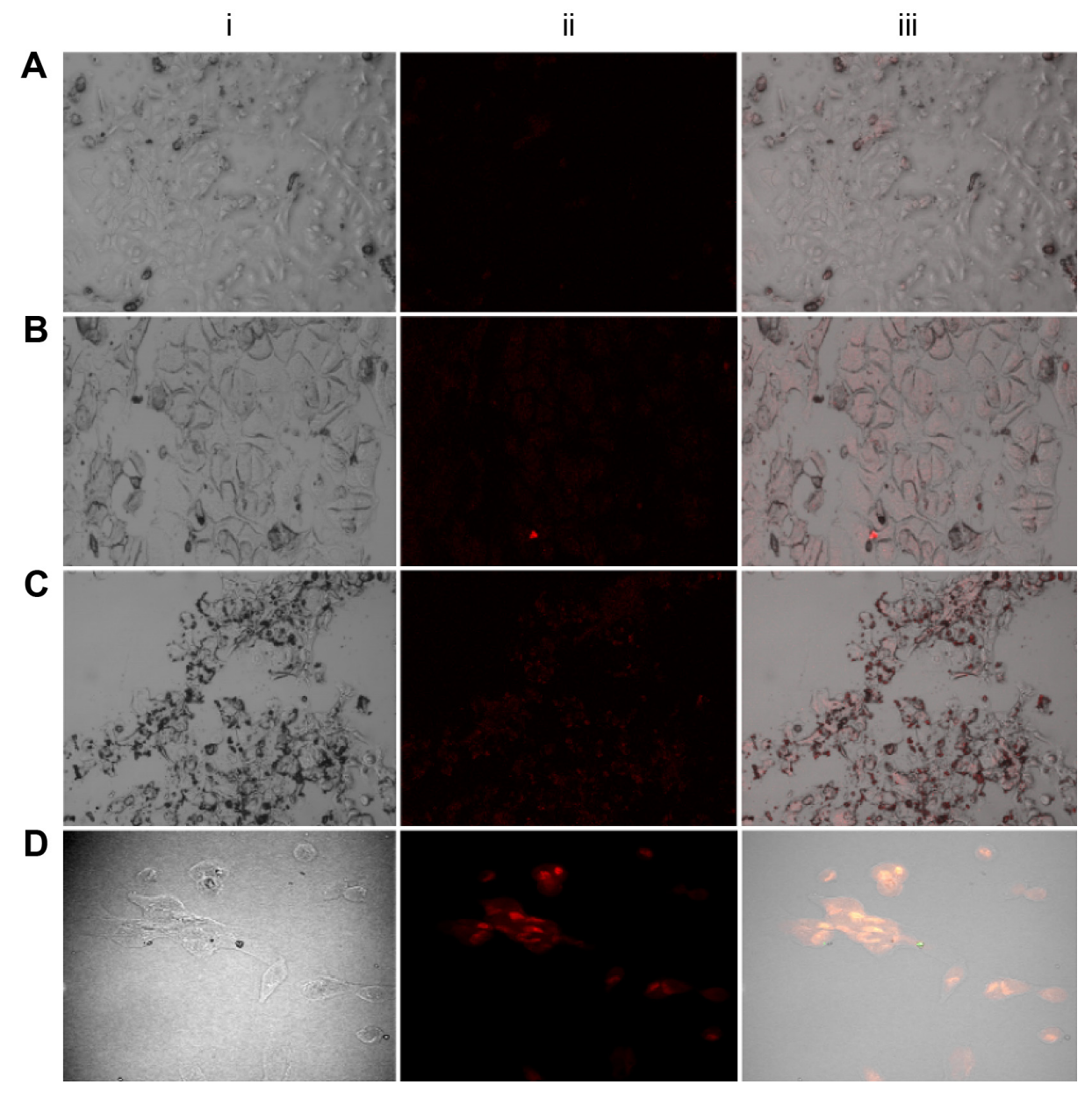

Figure 9 Confocal microscopic images of Mn:ZnS-treated MCF-7 cells (A), FACS-Mn:ZnS-treated MCF-7 cells (B), MDA-MB-23I cells (C), and MCF-I0 cells (D), respectively. Note: From each zone, (i) represents the normal transmission image, (ii) represents the fluorescence image, and (iii) represents the combination/overlaying of both transmission and fluorescence images of the corresponding cells.

Abbreviations: FACS-Mn:ZnS, folic acid-chitosan stabilized $\mathrm{Mn}^{2+}$-doped $\mathrm{ZnS}$; $\mathrm{ZnS}$, zinc sulfate. 
conjugated FA composites (Figure 9D-iii). Thus, the observed fluorescence property demonstrated by the FR-overexpressing cells (Figure 9B and C) supported the hypothesis that FACS$\mathrm{Mn}: \mathrm{ZnS}$ QDs can serve as suitable contrasting agents for the online targeted imaging of cancerous cells.

\section{Conclusion}

In conclusion, the present study indicates that the FACSMn:ZnS QDs can be synthesized entirely at room temperature and aqueous medium following simple wet chemistry method. A fast low cost process utilizes environmentally suitable materials such as CS and FA to stabilize the QDs and to formulate the composite with targeted drug delivery and imaging functionalities. With that, this report not just provides information about the synthesis of targeted $\mathrm{Mn}: \mathrm{ZnS}$ QDs, but also serves as a reference for the characterization of those QDs by means of various instrumental techniques such as XRD, XRF, XPS, UV-Vis, FTIR, HRTEM, FESEM, EDAX, TGA, and fluorescence. From the results obtained so far, we are convinced that the doping of Mn-atom impurities will significantly enhance the luminescence centers of $\mathrm{ZnS}$ nanocrystals and will widely support the considerable interest for the use and application of doped $\mathrm{ZnS}$ QDs as excellent materials for targeted fluorescence imaging studies. Of greater interest, the in vitro cytotoxicity study of the composite shows that the QDs are nontoxic to human breast cell lines and demonstrated specific cellular uptake by FR-expressing cancer cells, emitting fluorescence efficiency in the process. Thus, following the effective encapsulation of the QDs with biodegradable polymer and conjugated with a targeting ligand, the as-synthesized FACS-Mn:ZnS composite can further support the ongoing effort toward the effective targeted drug delivery and imaging of tumor-bearing cells.

\section{Acknowledgments}

IBB acknowledges Ministry of Education, Malaysia (5524420) for the funding. The authors would also like to thank the Faculty of Science and Institute of Advanced Technology (Universiti Putra Malaysia) for providing the instrumental facility. IBB acknowledges Adamawa State University, Mubi, Nigeria for the financial support through TETFund.

\section{Disclosure}

The authors report no conflicts of interest in this work.

\section{References}

1. Janib SM, Moses AS, MacKay JA. Imaging and drug delivery using theranostic nanoparticles. Adv Drug Deliver Rev. 2010;62:1052-1063.
2. Bwatanglang IB, Mohammad F, Yusof NA. Role of multifunctional nanomaterials in disease diagnosis and therapy. J Chem Pharm Res. 2010; 6:821-844.

3. Kumar CSSR, Mohammad F. Magnetic nanomaterials for hyperthermiabased therapy and controlled drug delivery. Adv Drug Deliver Rev. 2011; 63:789-808.

4. Mathew ME, Mohan JC, Manzoor K, et al. Folate conjugated carboxymethyl chitosan-manganese doped zinc sulphide nanoparticles for targeted drug delivery and imaging of cancer cells. Carbohyd Polym. 2012;80:442-448.

5. Bharali DJ, Mousa SA. Emerging nanomedicines for early cancer detection and improved treatment: current perspective and future promise. Pharmacol Ther. 2010;128:324-335.

6. Labiadh H, Chaabane TB, Piatkowski D, et al. Aqueous route to color-tunable Mn-doped ZnS quantum dots. Mater Chem Phys. 2013; 140:674-682.

7. Sen S, Sharma P, Solanki CS. Fabrication and characterization of ZnS: Mn nanoparticles for spectral shifting. J Trends Chem. 2010;1:14-17.

8. Krsmanović Whiffen RM, Jovanović DJ, Antić Z, et al. Structural, optical and crystal field analyses of undoped and Mn 2+-doped $\mathrm{ZnS}$ nanoparticles synthesized via reverse micelle route. $J$ Lumin. 2014;146:133-140.

9. Sharma M, Singh S, Pandey O. Excitation induced tunable emission in biocompatible chitosan capped $\mathrm{ZnS}$ nanophosphors. $J$ Appl Phys. 2010;107:104319.

10. Kole A, Tiwary C, Kumbhakar P. Room temperature synthesis of Mn2+ doped $\mathrm{ZnS}$ d-dots and observation of tunable dual emission: effects of doping concentration, temperature, and ultraviolet light illumination. J Appl Phys. 2013;113:114308.

11. Cao L, Huang H. Effect of irradiation on the luminescence in ZnS: Mn 2+ nanoparticles. J Lumin. 2005;114:293-298.

12. Cruz AB, Shen Q, Toyoda T. Studies on the effect of UV irradiation on Mn-doped ZnS nanoparticles. Mater Sci Eng C. 2005;25:761-765.

13. Yu Z, Ma X, Yu B, Pan Y, Liu Z. Synthesis and characterization of $\mathrm{ZnS}: \mathrm{Mn} / \mathrm{ZnS}$ core/shell nanoparticles for tumor targeting and imaging in vivo. J Biomater Appl. 2012;28:232-240.

14. Rezanejade BG, Hooshyar Z. CdTe quantum dots embedded in multidentate biopolymer based on Salep: characterization and optical properties. J Chem. 2013:1-6.

15. Zhou C, Shen H, Guo Y, et al. A versatile method for the preparation of water-soluble amphiphilic oligomer-coated semiconductor quantum dots with high fluorescence and stability. J Colloid Interf Sci. 2010;344:279-285.

16. Jian W, Zhuang J, Yang W, Bai Y. Improved photoluminescence of $\mathrm{ZnS}$ : Mn nanocrystals by microwave assisted growth of $\mathrm{ZnS}$ shell. J Lumin. 2007;126:735-740.

17. Yuan Q, Hein S, Misra R. New generation of chitosan-encapsulated $\mathrm{ZnO}$ quantum dots loaded with drug: synthesis, characterization and in vitro drug delivery response. Acta Biomater. 2010;6:2732-2739.

18. Eychmüller A, Rogach AL. Chemistry and photophysics of thiolstabilized II-VI semiconductor nanocrystals. Pure Appl Chem. 2000; 72:179-188.

19. Ban R, Li J, Cao J, Zhang P, Zhang J, Zhu JJ. Highly luminescent glutathione-capped $\mathrm{ZnS}: \mathrm{Mn} / \mathrm{ZnS}$ core/shell doped quantum dots for targeted mannosyl groups expression on the cell surface. Anal Method. 2013; 5:5929-5937.

20. Liu LH, Guo K, Venkatraman SS, et al. Biologically active core/shell nanoparticles self-assembled from cholesterol-terminated PEG-TAT for drug delivery across the blood-brain barrier. Biomaterials. 2008; 29:1509-1517.

21. Garcia-Bennett A, Nees M, Fadeel B. In search of the holy grail: folatetargeted nanoparticles for cancer therapy. Biochem Pharmacol. 2011; 81:976-984.

22. Medintz IL, Uyeda HT, Goldman ER, et al. Quantum dot bioconjugates for imaging, labelling and sensing. Nat Mater. 2005;4:435-446.

23. Jianghong R, Anca DA, Yao H. Fluorescence imaging in vivo: recent advances. Curr Opin Biotechnol. 2007;18:17-25. 
24. Dahan M, Levi S, Luccardini C, et al. Diffusion dynamics of glycine receptors revealed by single-quantum dot tracking. Science. 2003; 302:442-445.

25. Parak WJ, Boudreau R, Gros ML, et al. Cell motility and metastatic potential studies based on quantum dot imaging of phagokinetic tracks. Adv Mater. 2002;14:882-885.

26. Mingyong H, Gao XH, Su JZ, Nie SM. Quantum-dot-tagged microbeads for multiplexed optical coding of biomolecules. Nat Biotechnol. 2001;19:631-635.

27. Ulbrich K, Šubr VR. Polymeric anticancer drugs with $\mathrm{pH}$-controlled activation. Adv Drug Deliver Rev. 2004;56:1023-1050.

28. Xie Z, Guan HL, Chen X, et al. A novel polymer-paclitaxel conjugate based on amphiphilic triblock copolymer. Controlled Release. 2007; 117:210-216.

29. Manzoor K, Johny S, Thomas DSS, Menon D, Nair S. Bio-conjugated luminescent quantum dots of doped $\mathrm{ZnS}$ : a cyto-friendly system for targeted cancer imaging. Nanotechnology. 2009;20:065102.

30. Castillo JJ, Rindzevicius T, Novoa LV, et al. Non-covalent conjugates of single-walled carbon nanotubes and folic acid for interaction with cells over-expressing folate receptors. J Mater Chem B. 2013;1: 1475-1481.

31. Nakayama-Ratchford N, Bangsaruntip S, Sun X, et al. Noncovalent functionalization of carbon nanotubes by fluorescein-polyethylene glycol: supramolecular conjugates with $\mathrm{pH}$-dependent absorbance and fluorescence. J Am Chem Soc. 2007;129:2448-2449.

32. Bhattacharya R, Patra CR, Earl A, et al. Attaching folic acid on gold nanoparticles using noncovalent interaction via different polyethylene glycol backbones and targeting of cancer cells. Nanomed Nanotechnol Biol Med. 2007;3:224-238.

33. Song H, Su C, Cui W, et al. Folic acid-chitosan conjugated nanoparticles for improving tumor-targeted drug delivery. BioMed Res Int. 2013:1-6.

34. Ke X, Ng VWL, Ono RJ, et al. Role of non-covalent and covalent interactions in cargo loading capacity and stability of polymeric micelles. J Control Release. 2014;193:9-26.

35. Sahu SK, Mallick SK, Santra S, et al. In vitro evaluation of folic acid modified carboxymethyl chitosan nanoparticles loaded with doxorubicin for targeted delivery. J Mater Sci Mater Med. 2010;21:1587-1597.

36. Maity AR, Saha A, Roy A, Jana NR. Folic acid functionalized nanoprobes for fluorescence, dark field, and dual imaging-based selective detection of cancer cells and tissue. Chem Plus Chem. 2013;78: 259-267.

37. Chang-Cheng Y, Verma Y, Rotello VM. Engineering the nanoparticlebiomacromolecule interface. Soft Mater. 2006;2:190-204.

38. Ding J, Chen L, Xiao C, et al. Noncovalent interaction-assisted polymeric micelles for controlled drug delivery. Chem Commun. 2014;50: 11274-11290.
39. Rinaudo M, Pavlov1 G, Desbrieres J. Influence of acetic acid concentration on the solubilization of chitosan. Polymer. 1999;40:7029-7032.

40. Mohammad F, Arfin T. Cytotoxic effects of polystyrene-titaniumarsenate composite in cultured $\mathrm{H} 9 \mathrm{c} 2$ cardiomyoblasts. Bull Environ Contam Toxicol. 2013;91:689-696.

41. Ummartyotin S, Bunnak N, Juntaro J, et al. Synthesis and luminescence properties of $\mathrm{ZnS}$ and metal $(\mathrm{Mn}, \mathrm{Cu})$-doped-ZnS ceramic powder. Solid State Sci. 2012;14:299-304.

42. Park J, Dvoracek C, Lee KH, et al. CuInSe/ZnS core/shell NIR quantum dots for biomedical imaging. Small. 2011;7:3148-3152.

43. Han SJ, Rathinaraj P, Park SY, et al. Specific intracellular uptake of herceptin-conjugated $\mathrm{CdSe} / \mathrm{ZnS}$ quantum dots into breast cancer cells. BioMed Res Int. 2014;2014:1-9.

44. Ramanery FP, Mansur AA, Mansur HS. One-step colloidal synthesis of biocompatible water-soluble $\mathrm{ZnS}$ quantum dot/chitosan nanoconjugates. Nanoscale Res Lett. 2013;8:1-13.

45. Geszke M, Murias M, Balan L, et al. Folic acid-conjugated core/shell $\mathrm{ZnS}: \mathrm{Mn} / \mathrm{ZnS}$ quantum dots as targeted probes for two photon fluorescence imaging of cancer cells. Acta Biomater. 2011;7:1327-1338.

46. Kolmykov O, Coulon J, Lalevée J, et al. Aqueous synthesis of highly luminescent glutathione-capped $\mathrm{Mn} 2+$-doped $\mathrm{ZnS}$ quantum dots. Mat Sci Eng C. 2014;44:17-23.

47. Brus L. Chemical approaches to semiconductor nanocrystals. J Phys Chem Solids. 1998;59:459-465

48. Kripal R, Gupta AK, Mishra SK, et al. Photoluminescence and photoconductivity of $\mathrm{ZnS}$ : Mn 2+ nanoparticles synthesized via co-precipitation method. Spectrochim Acta A. 2010;76:523-530.

49. Wageh S, Ling ZS, Xu-Rong X. Growth and optical properties of colloidal ZnS nanoparticles. J Cryst Growth. 2003;255:332-337.

50. Joicy S, Saravanan R, Prabhu D, et al. $\mathrm{Mn}^{2+}$ ion influenced optical and photocatalytic behaviour of $\mathrm{Mn}-\mathrm{ZnS}$ quantum dots prepared by a microwave assisted technique. RSC Adv. 2014;4:44592-44599.

51. Biggs MM, Ntwaeaborwa OM, Terblans JJ, Swart HC. Characterization and luminescent properties of SiO 2: ZnS: Mn 2+ and ZnS: Mn 2+ nanophosphors synthesized by a sol-gel method. Physica B Condensed Matter. 2009;404:4470-4475.

52. Soltani N, Saion E, Erfani M, et al. Influence of the polyvinyl pyrrolidone concentration on particle size and dispersion of $\mathrm{ZnS}$ nanoparticles synthesized by microwave irradiation. Int J Mol Sci. 2012; 13:12412-12427.

53. Ni Y, Yin GG, Hong J, Xu Z. Rapid fabrication and optical properties of zinc sulfide nanocrystallines in a heterogeneous system. Mater Res Bull. 2004;39:1967-1972.
International Journal of Nanomedicine

\section{Publish your work in this journal}

The International Journal of Nanomedicine is an international, peerreviewed journal focusing on the application of nanotechnology in diagnostics, therapeutics, and drug delivery systems throughout the biomedical field. This journal is indexed on PubMed Central, MedLine, CAS, SciSearch ${ }^{\circledR}$, Current Contents ${ }^{\circledR} /$ Clinical Medicine,
Dovepress

Journal Citation Reports/Science Edition, EMBase, Scopus and the Elsevier Bibliographic databases. The manuscript management system is completely online and includes a very quick and fair peer-review system, which is all easy to use. Visit http://www.dovepress.com/ testimonials.php to read real quotes from published authors. 